\title{
NCSBN's Environmental Scan A Portrait of Nursing and Healthcare in 2020 and Beyond
}

\author{
National Council of State Boards of Nursing
}




\section{CONTENTS}

January $2020 \bullet$ Volume io - Issue 4 Supplement

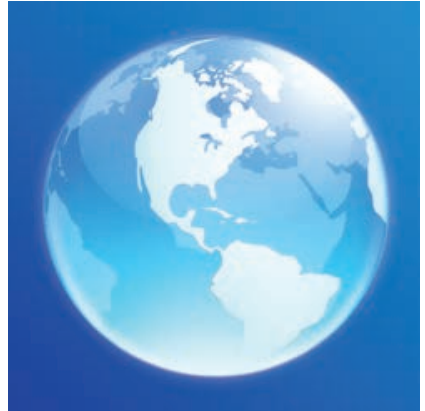

Advancing nursing excellence for public protection
200 Years since the Birth of Florence Nightingale . . . . . . . . . . S3

The U.S. Nursing Workforce . . . . . . . . . . . . . . . . . . . . . S3

Registered Nurses and Licensed Practical Nurses/Licensed Vocational Nurses . . . . . . . . . . S3

Impact of the Pending Physician Shortfall . . . . . . . . . . . . . . . . S5

Advanced Practice Registered Nurses . . . . . . . . . . . . . . . . . . . . . S6

Healthcare Support Personnel . . . . . . . . . . . . . . . . . . . . . S7

Regulatory Implications . . . . . . . . . . . . . . . . . . . . . S7

Nursing Education . . . . . . . . . . . . . . . . . . . . . S7

Education Trends to Predict Future Workforce . . . . . . . . . . . . . . . . . S8

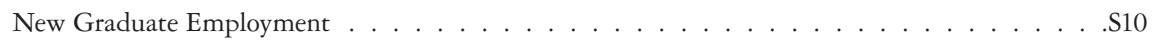

Advancing Nursing Education . . . . . . . . . . . . . . . . . . . . . . S12

Nursing Faculty Needs . . . . . . . . . . . . . . . . . . . . . . . . . . . . . . . S13

Emerging Education Subjects. . . . . . . . . . . . . . . . . . . . . . . . . . . . . . . . .

Social Determinants of Health in Nursing Education . . . . . . . . . . . . . . . . . . . . S14

Teaching Diagnosis . . . . . . . . . . . . . . . . . . . . . . 15

Regulatory Implications . . . . . . . . . . . . . . . . . . . . . . . . . . . . . . . . . . . . . . . .

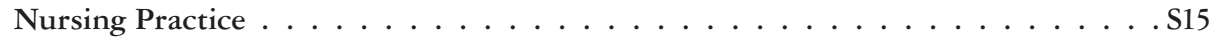

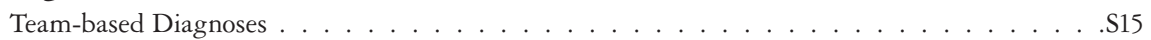

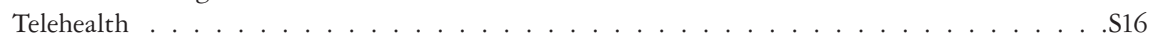

Regulatory Implications . . . . . . . . . . . . . . . . . . . . . S16

Patient Safety, Healthcare Quality, and Healthcare Delivery. . . . . . . . . . S16

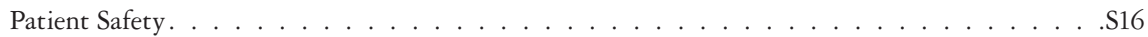

Disparities and Inequities. . . . . . . . . . . . . . . . . . . . . . . . . . . . . . . . . . . . . . . . . . . . . . . . .

Workplace Culture . . . . . . . . . . . . . . . . . . . . S17

Advancements in Technology . . . . . . . . . . . . . . . . . . . . . . S18

Artificial Intelligence $\ldots \ldots \ldots \ldots \ldots \ldots . \ldots \ldots . \ldots \ldots$. . . . . . . . . . . . .

Regulatory Implications . . . . . . . . . . . . . . . . . . . . . . . . S18

Public Policy . . . . . . . . . . . . . . . . . . . . . . . . S19

Removing Barriers to the Profession: Occupational Licensure Reform . . . . . . . . . . . . . S19

Student Loan Defaults . . . . . . . . . . . . . . . . . . . . . . . . . . . S19

Military Service Members and Spouse Occupational Licensing . . . . . . . . . . . . . . . . . . S19

Criminal Justice Reform . . . . . . . . . . . . . . . . . . . . . . . . S20

Removing Barriers to Practice: Compacts and Consensus . . . . . . . . . . . . . . . . S20

The Nurse Licensure Compact . . . . . . . . . . . . . . . . . . . . . . . . . . . . S20

The APRN Consensus Model . . . . . . . . . . . . . . . . . . . . . . . S21

Trade and Immigration $\ldots \ldots \ldots \ldots \ldots \ldots \ldots \ldots \ldots \ldots$ S22

School Nurses. . . . . . . . . . . . . . . . . . . . . . . . . . . . . . . S22

Veterans Affairs . . . . . . . . . . . . . . . . . . . . . S22

Regulatory Implications . . . . . . . . . . . . . . . . . . . . . . . S23

Social Issues Affecting Nursing Regulation. . . . . . . . . . . . . . . . . . S23

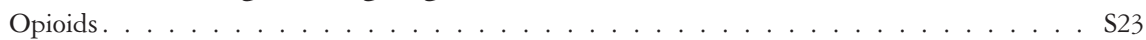

Initiatives Addressing the Opioid Epidemic . . . . . . . . . . . . . . . S23

Medication-Assisted Treatment. . . . . . . . . . . . . . . . . . . . S24

Cannabis Research . . . . . . . . . . . . . . . . . . . . . . . . . . . . . . . . . . . . . . . . .

Influenza Vaccines and U.S. Healthcare Workers . . . . . . . . . . . . . . . S25

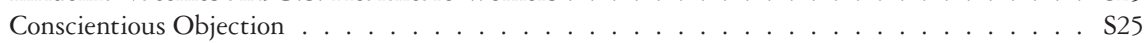

Regulatory Implications . . . . . . . . . . . . . . . . . . . . S26

Summary and Conclusions . . . . . . . . . . . . . . . . . S26

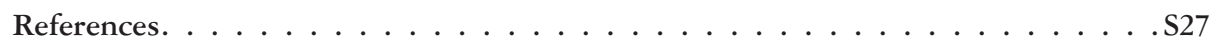

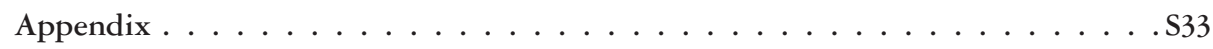




\section{NCSBN's Environmental Scan A Portrait of Nursing and Healthcare in 2020 and Beyond}

Keywords: nursing education and practice, nursing regulation, nursing workforce, healthcare delivery, public policy

\section{Years since the Birth of Florence Nightingale}

May 12, 2020, will be the 200th anniversary of the birth of Florence Nightingale, who is recognized as the founder of modern nursing and the first nurse researcher. Nightingale set standards for the profession that continue to serve as precedents of nursing excellence. These include: (a) setting high standards for nursing education; (b) implementing interventions based on data and evidence; (c) conducting nursing research; (d) giving attention to the role of environmental, social, and political factors and their influence on patient care outcomes; and (e) promoting public protection (Bostridge, 2015). Nightingale's leadership, along with the leadership of those who followed in her footsteps, transformed nursing into a profession that today numbers more than 20 million nurses worldwide (National Council of State Boards of Nursing [NCSBN], 2019a).

As we begin a yearlong celebration in honor of Nightingale, the Journal of Nursing Regulation dedicates this environmental scan to her influence and the accomplishments of other nursing leaders who guided the early days of the profession. More importantly, however, this supplement looks toward the future. This year's environmental scan presents the current nursing workforce and healthcare milieu that provides the backdrop for nursing regulation, discusses issues impacting nursing and regulation, and addresses some of the challenges laying ahead in 2020 and beyond.

\section{The U.S. Nursing Workforce}

Much of Florence Nightingale's legacy involves laying the foundation for a strong nursing workforce to extend into future generations, from establishing the first nursing education programs not affiliated with religious service to expanding the role of women in the workforce (Bostridge, 2015). The precedent of workforce planning she set is even more urgent today as an aging population will increase demand for healthcare providers in unprecedented ways.

\section{Registered Nurses and Licensed Practical Nurses/Licensed Vocational Nurses}

The National Council of State Boards of Nursing's (NCSBN) National Nursing Database tracks the number of U.S. licensed nurses from 56 boards of nursing (BONs) daily. There were 4,096,607 registered nurses (RNs) and 920,655 licensed practical nurses/licensed vocational nurses (LPN/LVNs) in the United States as of October 2019 (NCSBN National Nursing Database, 2019a). The most recent Occupational Employment Statistics data from May 2018 indicate 2,951,970 RNs and 701,650 LPN/LVNs were employed in the United States (U.S. Bureau of Labor Statistics [BLS], 2019b). Figures 1 and 2 illustrate a growing RN employment and an LPN/LVN employment that is holding steady. 


\section{FIGURE 1}

\section{Number of Employed RNs and LPN/LVNs in the United States}
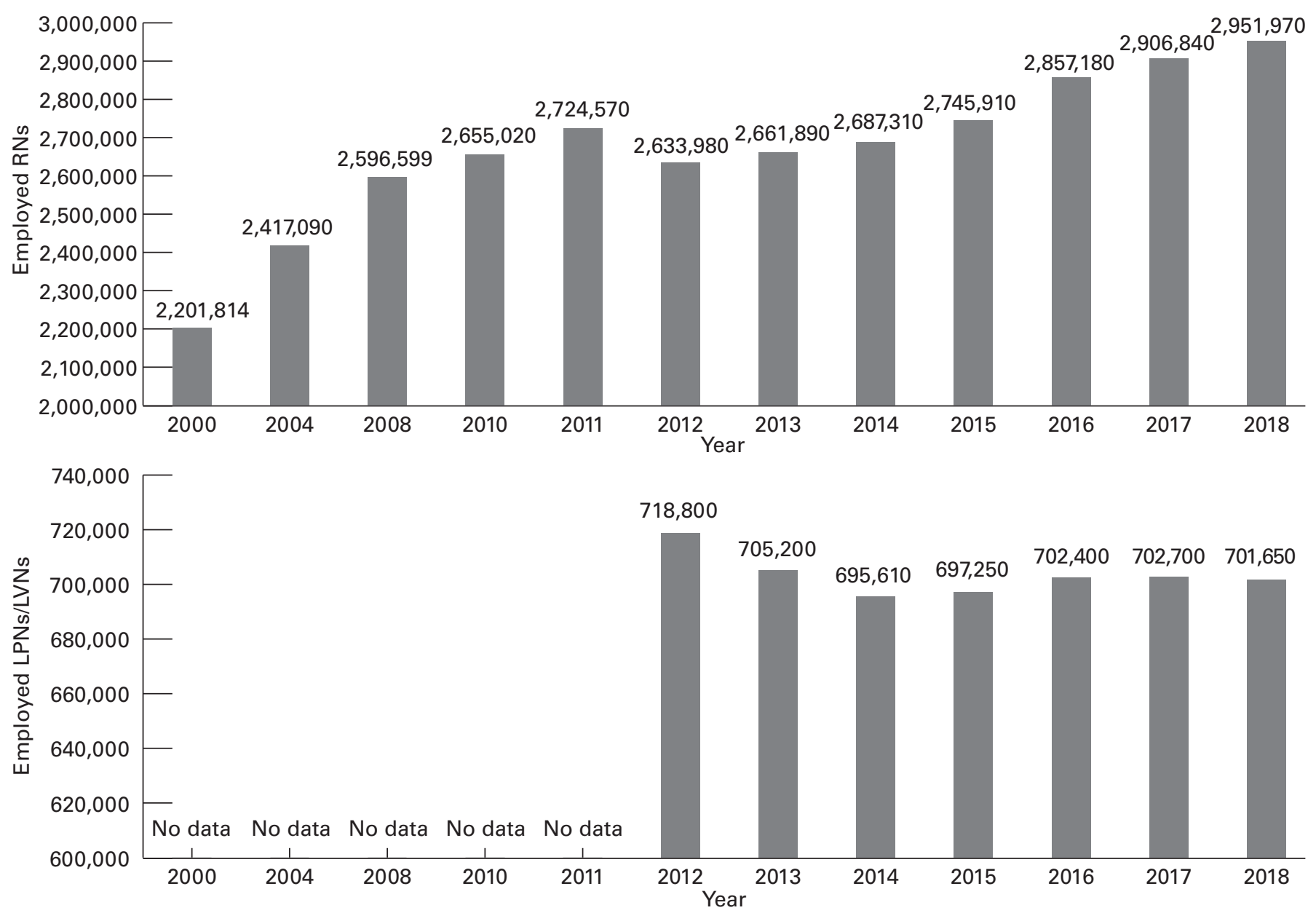

Note. The 2010-2018 statistics were taken from the semiannual Occupational Employment Statistics (OES) survey published by the U.S. Bureau of Labor Statistics (2018). The 2000, 2004, and 2008 were taken from the U.S. Department of Health and Human Services Health Resources Services Administration (HRSA)'s National Sample Survey of Registered Nurses (2010).

The number of employed RNs per population in each state varies widely across the country, from slightly under $700 \mathrm{RNs}$ per 100,000 people in Utah to nearly 1,600 RN per 100,000 people in the District of Columbia (Figure 2) (U.S. Department of Labor Statistics, 2019; U.S. Census Bureau, 2019). Other states with approximately 700 RNs per 100,000 people are Georgia and Texas. Conversely, states like South Dakota (1,446 RNs per 100,000 people), Minnesota (1,230 RNs per 100,000 people), and Delaware (1,224 RNs per 100,000 people) have the highest ratios of employed RNs per population. The ratio of employed LPN/LVNs is between 65 and 85 per 100,000 people in Utah, Alaska, and Hawaii and over 400 per 100,000 in Louisiana and Arkansas. 


\section{FIGURE 2}

\section{Number of Employed RNs and LPNs/LVNs per 100,000 Population}

\section{RNs}

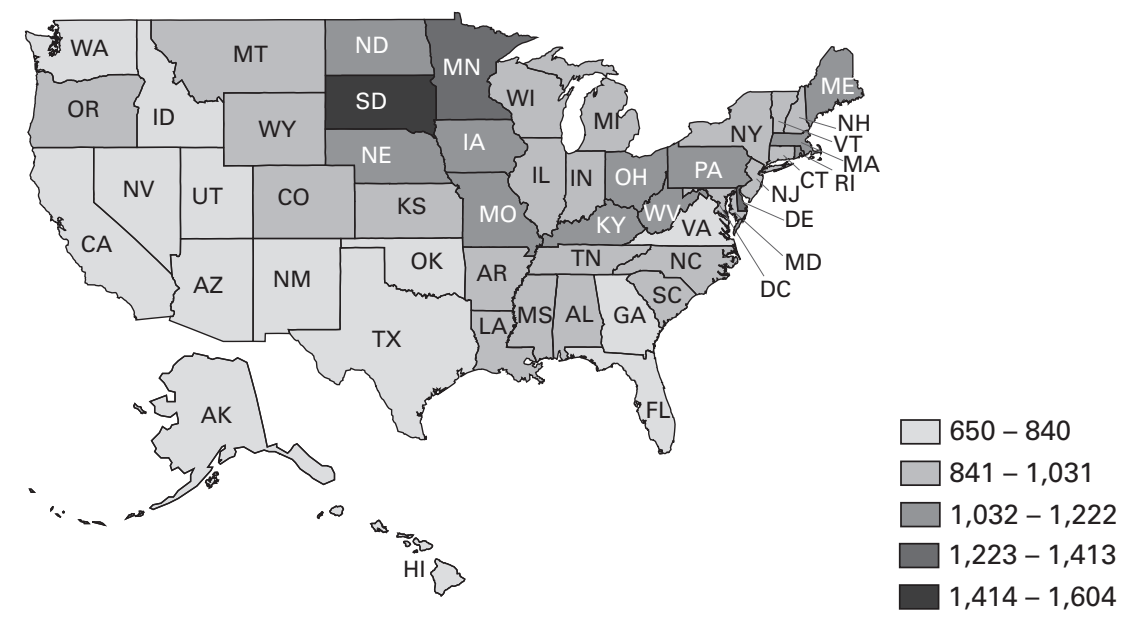

LPNs/LVNs

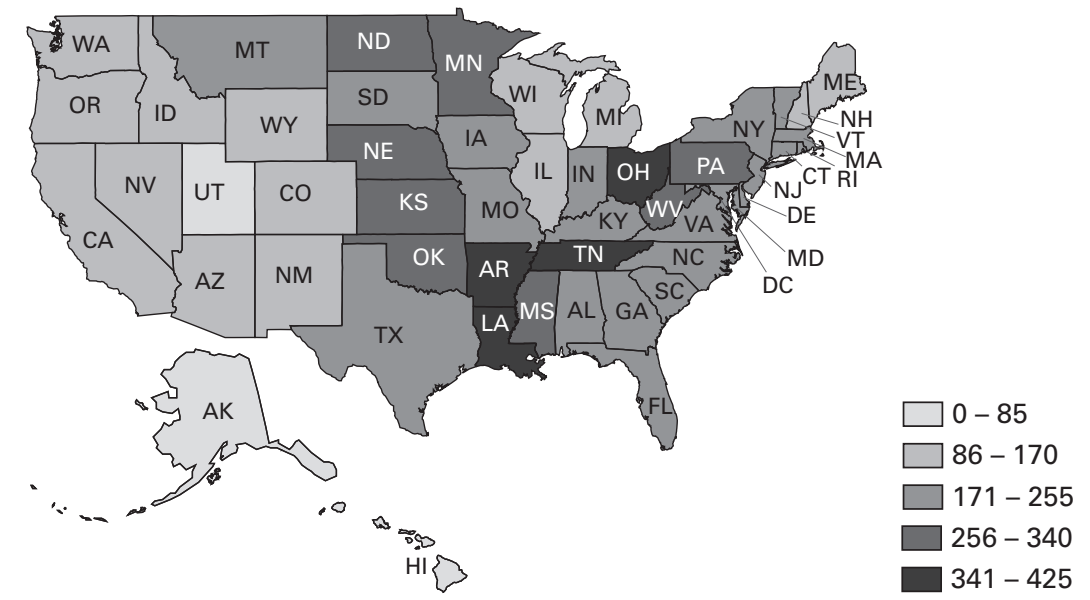

Note. Employed RNs and LPNs/LVNs per 100,000 people by state as of May 2017.

Source: U.S. Bureau of Labor Statistics, 2018a; 2018b; U.S. Census Bureau, 2018a.

The maps in Figure 2 provide a quick state-level snapshot of the supply of employed nurses; however, there are regional differences within each state that could be different from the overall state-level view. These regional differences within states are often the main concern for individuals involved in studying and monitoring the nursing workforce. For instance, California has one of the lowest employed nurse-to-population ratios; however, within the state, city centers such as San Francisco may have very high nurse-to-population ratios, whereas rural areas of the state may have very low nurse-to-population ratios. Within-state regional nurse employment numbers are available for download from the U.S. Bureau of Labor Statistics, (2019a).

\section{Impact of the Pending Physician Shortfall}

When considering the entire healthcare provider workforce, strong growth of all areas of the nursing workforce becomes even more important. In particular, the physician workforce is expected to fall significantly short of demand within the next 15 years. Although the number of physicians in the United States has grown over the last decade and continues to do so (Figure 3), the Association of American Medical Colleges (2019) estimates that demand for care will far outpace supply of physicians. By 2032, this shortage could be between 46,900 and 121,900 physicians. This will affect primary care, where the shortage may reach as high as 55,200 physicians, and specialty care which may see a shortage of up to 65,800 physicians (BLS, 2019b).

Since access to care will not be equitable in every geographic location, the Association of American Medical Colleges (2018) projects that the actual shortage numbers will likely be higher. This demand will be largely driven by the aging population since it is estimated the number of people over age 65 will grow by $48 \%$ by that year (Association of American Medical Colleges, 2019). 


\section{FIGURE 3}

\section{Number of Physicians in the United States, 2008-2018}

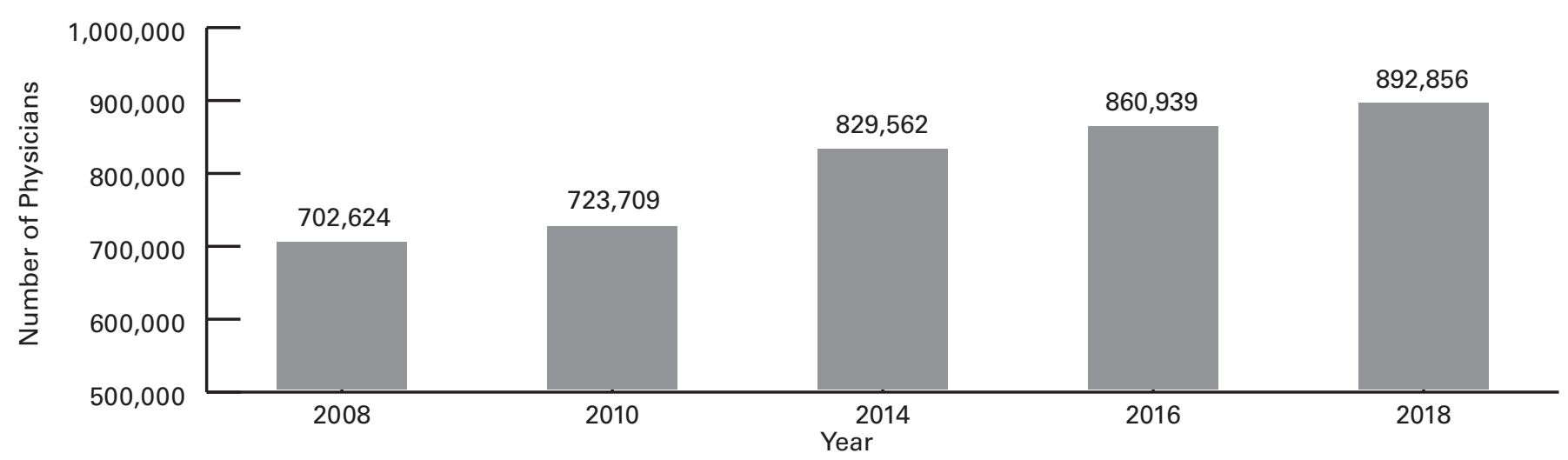

Source: AMA Master File, 2008-2018, as cited by Association of American Medical Colleges, 2008-2018.

This shortage will cause a cascade effect in all other healthcare professions, increasing demand for other types of providers and triggering employment growth at a much faster rate than the average job growth of 5\% (BLS, 2019a).

The main providers to alleviate this disparity, particularly in primary care, will be advanced practice registered nurses (APRNs) and physician assistants (PAs). Both provider types will see tremendous job growth by 2028; however, APRNs are more numerous, although estimating the total number of APRNs is challenging due to differences in categorization and licensure among the states.

\section{Advanced Practice Registered Nurses}

An annual comparison of the performance of state health systems again demonstrated the best performing states were those with unrestricted APRN scopes of practice. Restriction of APRN practice and prescribing does not correlate with better performance in healthcare outcomes. In fact, many of the states with the lowest scores were the most restrictive (Radley, Collins, \& Hayes 2019). This survey shows that frequently where access to quality care is needed the most, barriers are the most prevalent.

Nurse practitioners (NPs) are the largest APRN role, and since the U.S. Bureau of Labor Statistics (BLS) began tracking the role in 2012, the profession has grown by 59\% (BLS 2019b; Figure 4). As of May 2018, there were 6,250 certified nurse midwives (CNMs) (BLS, 2019c), and 42,620 certified registered nurse anesthetists (CRNAs) (BLS, 2019d). Certified nurse specialists (CNSs) numbers are not tracked independently at this time. For NPs, CNMs, and CRNAs, the BLS presently calculates job projections in aggregate and expects employment to grow 26\% overall by 2028 (BLS, 2019e). Continued state adoption of the Consensus Model for APRN Regulation, Licensure, Accreditation, Certification, and Education (The APRN Consensus Model) will increase uniformity in title and licensure of APRNS, thereby improving accuracy of workforce numbers reporting and the accuracy of future projections.

\section{FIGURE 4}

\section{Number of NPs in the United States, 2012-2018}

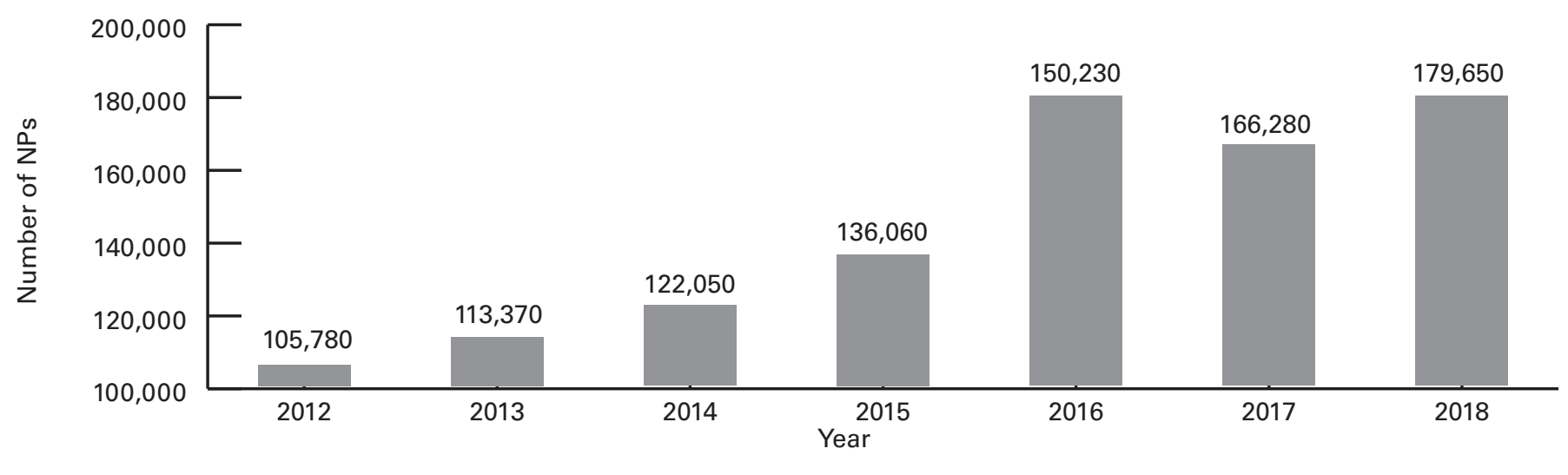




\section{Healthcare Support Personnel}

As mentioned, the aging population is the catalyst for the projected sharp increase in demand, and with a demand for higher-level providers comes increased demand for unlicensed assistive personnel. For tracking purposes, the BLS categorizes these professions as "healthcare support occupation," which is an umbrella category encompassing such roles as home health aides, nursing assistants, and medication assistants. In the United States, there were more than 4 million people employed in these roles in 2018 (Figure 5), and the BLS expects employment in these areas to skyrocket; however, growth will occur at different rates for different roles. For example, nursing assistants are expected to experience a $9 \%$ increase in demand by 2028, which is still above the typical job growth average of $5 \%$. Home health aides, who are instrumental in caring for aging populations, the demand is expected to increase by $36 \%$ during this time- possibly resulting in up to one million more people employed in that role (BLS, 2019f).

\section{FIGURE 5}

\section{Number of Healthcare Support Personnel in the United States, 2009-2018}

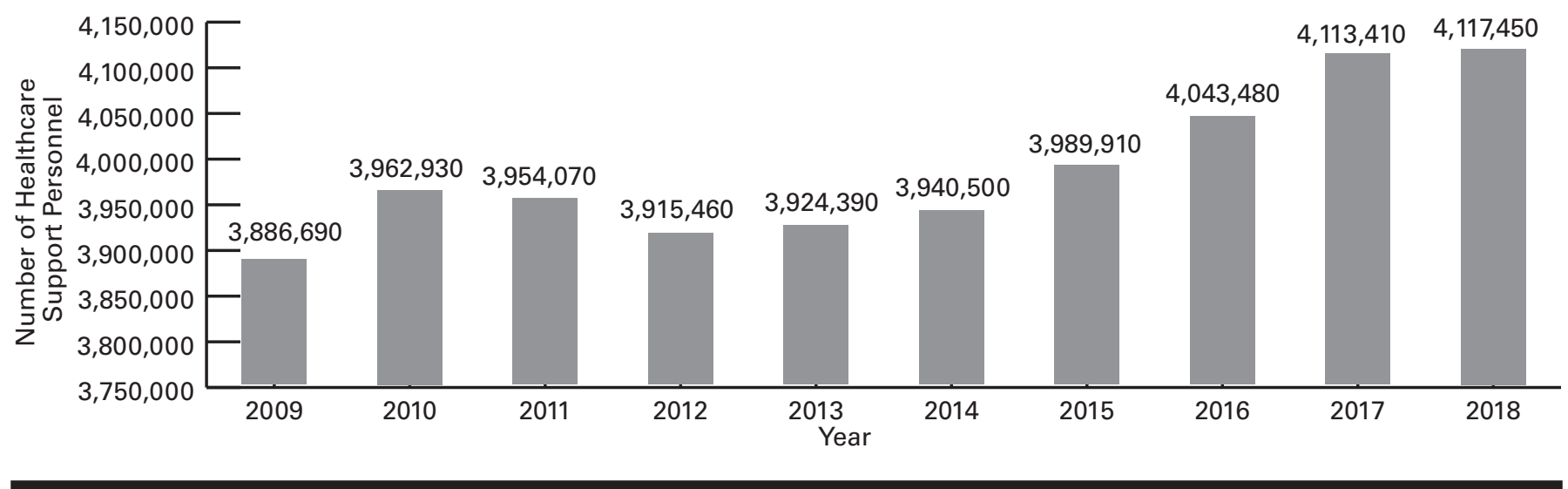

\section{Regulatory Implications}

To weather the huge demographic shift looming over the United States and the healthcare challenges it will bring, healthcare workers in all disciplines must be used as effectively as possible. This involves each provider working to the full extent of their education, which will be helpful in combatting the regional disparities indicated by the projections. As evidence suggests, APRNs who are not tethered by a collaborative practice agreement with a physician will relocate to medically underserved areas (Xue et al., 2018). Truly mitigating the effects of regional healthcare disparities also requires policies that promote mobility of providers and remove geographic barriers to practice, such as continued adoption of the Nurse Licensure Compact (NLC) and the promulgation of policies facilitating telehealth. These will help ensure all communities receive the care they need, no matter how medically underserved.

Having the state BONs contribute their APRN data to Nursys, the national nursing database, will provide a more accurate depiction of the APRN workforce. Adoption of the APRN Consensus Model elements continues to be a priority for NCSBN and state BONs.

\section{Nursing Education}

A fund chaired by the Duke of Cambridge allowed Florence Nightingale to establish the Nightingale Training School at St. Thomas's Hospital in 1860, the first training school for nurses that was not affiliated with religious life. Her book Notes on Nursing served as the nursing curriculum there. The "Nightingale Nurses" transformed healthcare throughout England, and within 2 decades, Nightingale Nurses were in leadership positions at major hospitals throughout the British Empire (Bostridge, 2015). One of Nightingale's mentees was American Linda Richards, who returned to the United States to establish nursing schools with the same high-quality curriculum. Richards became known as "America's first trained nurse" (Nutting E Dock, 1907).

In partnering with the World Health Organization (WHO, 2019), who declared 2020 as the International Year of the Nurse and the Midwife, the International Council of Nurses (ICN) and the Nursing Now Campaign (2018) acknowledged the strong link between the nursing workforce of the future and the nursing education of the present. Annette Kennedy, President of ICN, said this movement will "...highlight the importance of the need for more well-educated nurses, of investing in recruitment and retention strategies and of removing the barriers to the development of advanced nursing roles that are proving highly effective at expanding healthcare coverage" (International Council of Nurses, 2019). Therefore, it is essential to evaluate the current state of nursing to prepare for nursing's future in influencing healthcare. This includes evaluating the current and future nursing workforce and its growth potential by looking at 
the number of nursing education programs, enrollment, and NCLEX takers as well as assessing the status of academic progression and any hindrances in increasing nursing growth potential (i.e., faculty shortage lending to decreased nursing graduates). It also involves preparing the nursing workforce to manage important issues and learning appropriate strategies (e.g., social determinants of health and team-based diagnoses) to meet the growing challenges of healthcare in the United States.

\section{Education Trends to Predict Future Workforce}

NCSBN has been examining the trend of new U.S. RN and LPN education programs since 2003 and has been using these data as one method for predicting future workforce numbers. The percentage of growth since 2003 for RN programs is $59 \%$ and for LPN programs, $16 \%$, although, RN program growth has been stagnant since 2015 and LPN program growth has been steadily declining since 2013 (Figure 6). Despite the decreasing number of LPN programs, LPN/LVNs are crucial to the care of older adults in long-term care settings and patients in ambulatory care and community settings.

\section{FIGURE 6}

\section{Number of Approved Nursing Programs in the United States, 2003-2018}

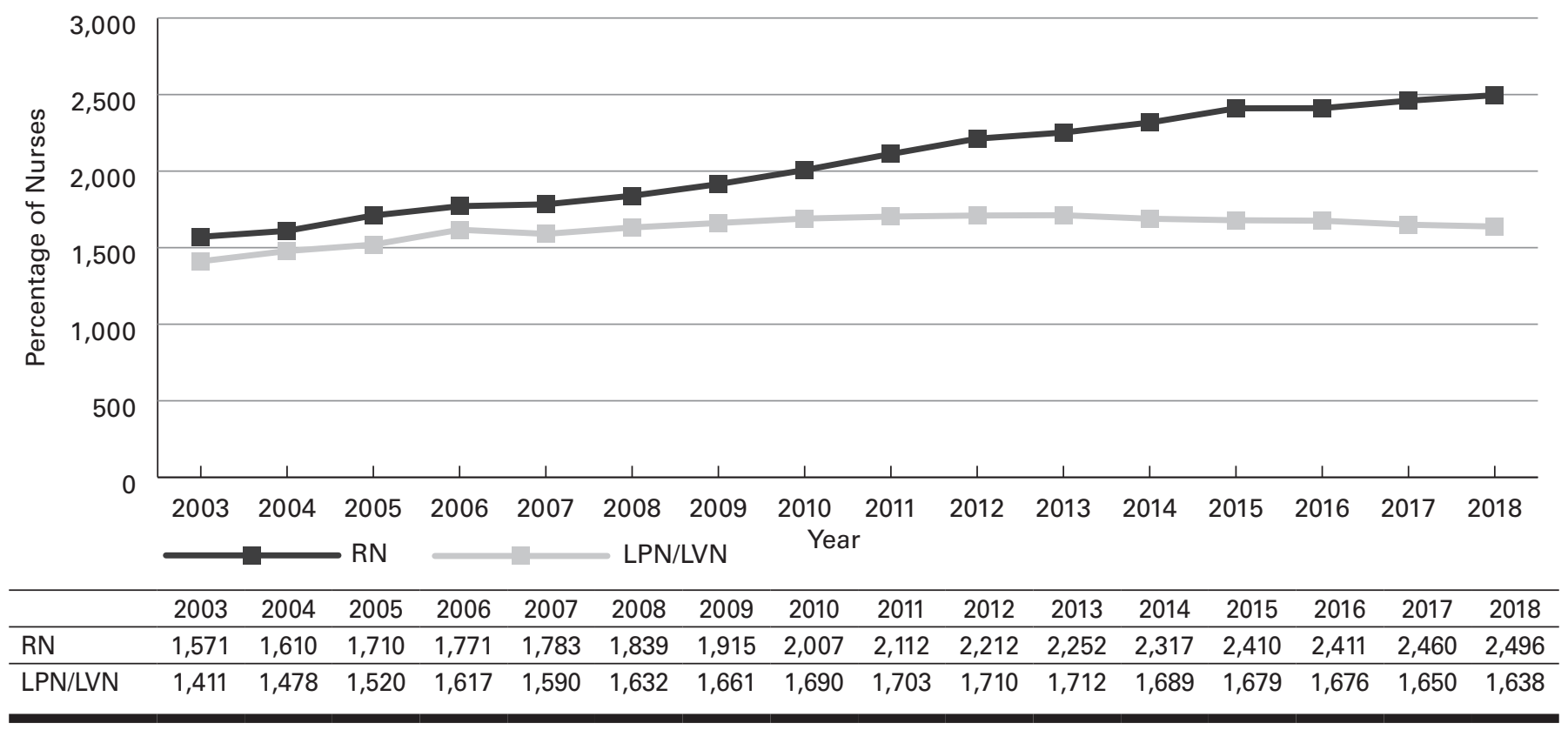

In addition to using nursing program growth to predict the future nursing workforce, NCSBN tracks the numbers of first-time NCLEX takers. Examination of the 10-year trend of first-time NCLEX takers in the United States shows that the number of RN firsttime NCLEX takers from 2014 to 2017 leveled off; however, there was an increase in RN first-time NCLEX takers in 2018. There is a steady decrease of first-time NCLEX-PN takers since 2012 with a very slight upturn from 2017 to 2018. (Figure 7) 


\section{FIGURE 7}

\section{0-year Trend of RN and LPN/LVN First-time NCLEX Takers}

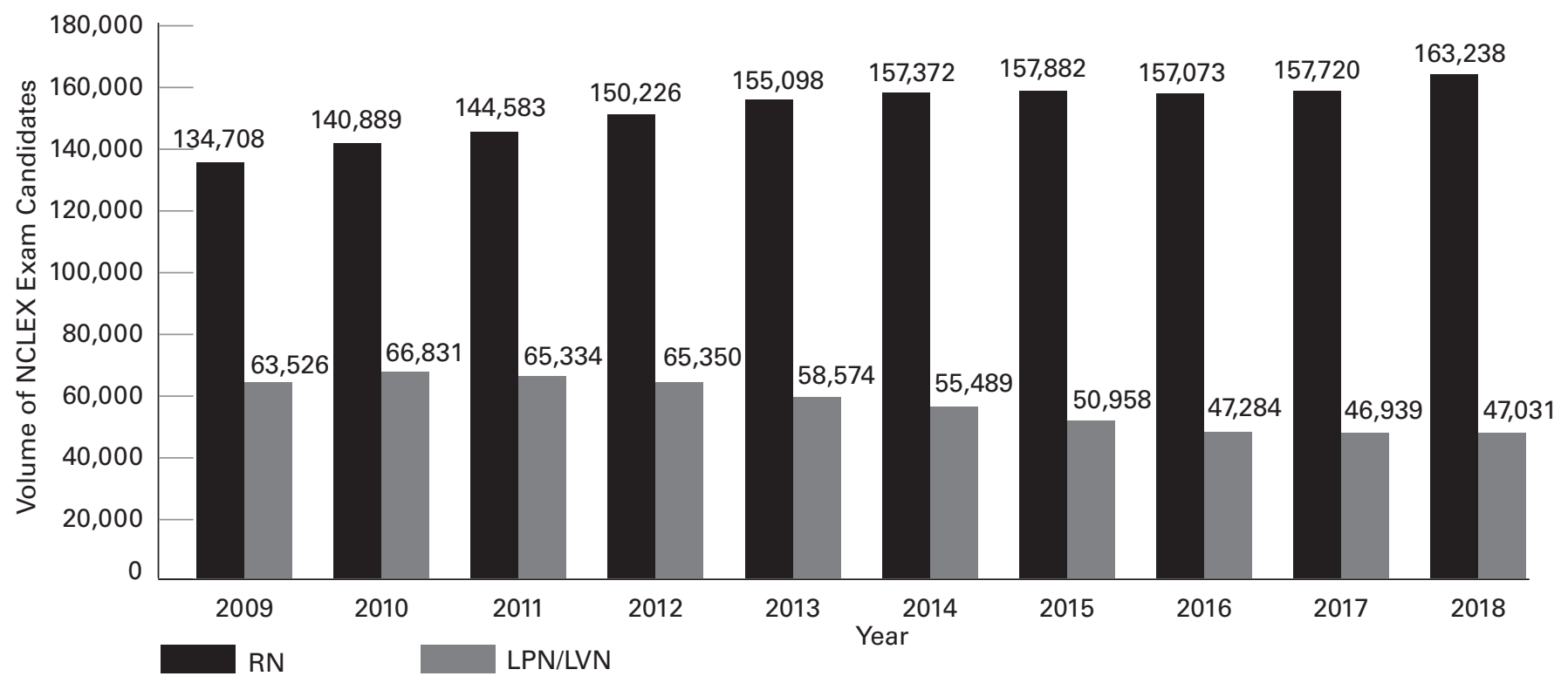

A 10-year analysis of U.S. RN first-time NCLEX takers by program type shows that associate-degree nursing (ADN) graduates still account for the largest number of nursing program graduates with the number of baccalaureate-degree nursing graduates not far behind. The growth rate of baccalaureate-degree graduates (52\%) surpassed the rate of growth of ADN graduates over the 10-year period (4\%) (Table 1), which can possibly be attributed to the focus in the past decade on building a baccalaureate-prepared nursing workforce (American Association of Colleges of Nursing [AACN], 2019a; Institute of Medicine [IOM], 2010; Tri-Council of Nursing, 2010).

TABLE 1

Ten-year Trend of U.S. RN First-time NCLEX Takers by Program Type, 2009-2018

\begin{tabular}{|c|c|c|c|c|}
\hline Year & Diploma & Associate Degree & Baccalaureate Degree & $\begin{array}{c}\text { Unclassified or Special } \\
\text { Codes }\end{array}$ \\
\hline 2009 & 3,677 & 78,665 & 52,241 & 125 \\
\hline 2011 & 3,476 & 82,764 & 58,146 & 97 \\
\hline 2012 & 3,173 & 84,517 & 62,535 & 41 \\
\hline 2015 & 2,607 & 84,379 & 70,857 & 39 \\
\hline 2016 & 2,745 & 81,653 & 72,637 & 34 \\
\hline 2017 & 2,222 & 79,511 & 75,944 & 43 \\
\hline 2018 & 1,968 & 82,000 & 79,235 & 35 \\
\hline
\end{tabular}

There is some variance in 2018 first-time pass rates of NCLEX-RN takers when separated by the level of education. The overall pass rate in 2018 for baccalaureate-degree graduates (91.57\%) was better than diploma (88.62\%) and associate-degree (85.11\%) graduates. Figure 8 shows that associate-degree graduates consistently achieved a lower pass rate than both the baccalaureate-degree and diploma graduates over the 10-year period from 2009 to 2018. 


\section{FIGURE 8}

\section{U.S. Educated RN First-time NCLEX Pass Rates by Program Type, 2009-2018}

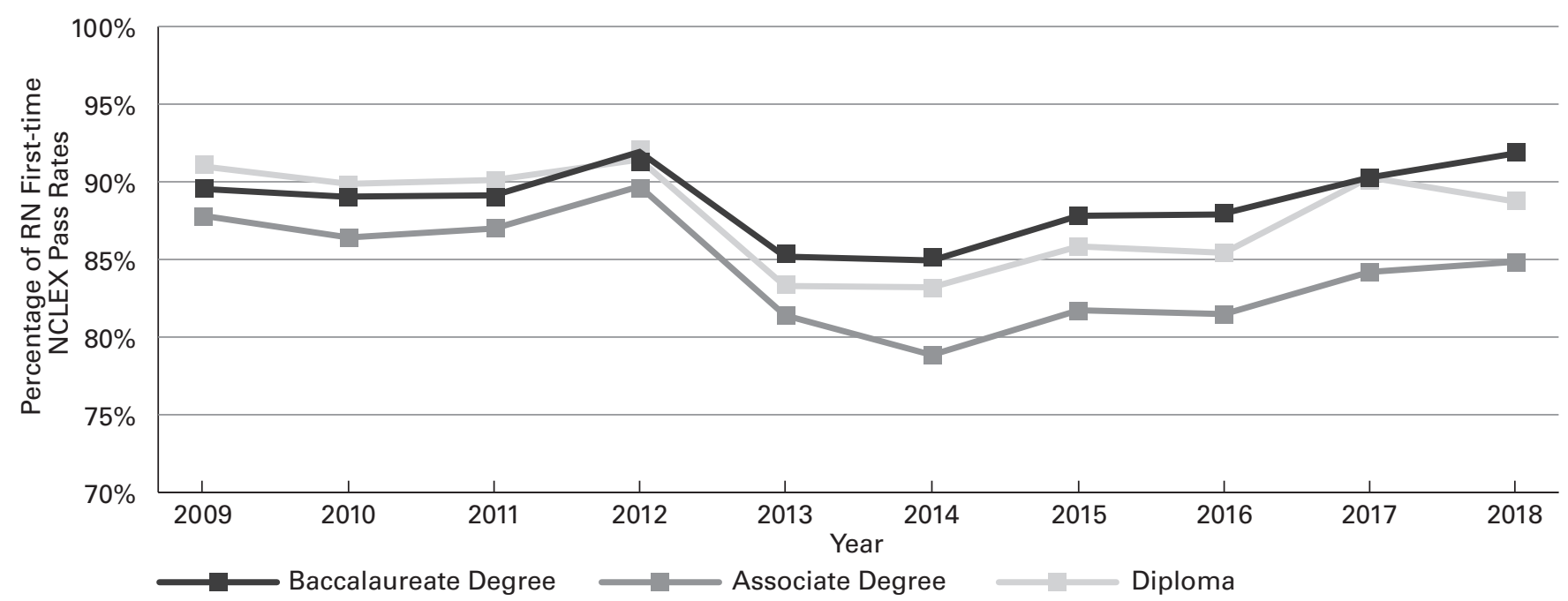

\section{New Graduate Employment}

The National Student Nurse Association (NSNA) surveys new graduate RNs annually to determine employment rates and potential obstacles to graduates acquiring initial employment. In NSNA's 2019 Survey $(n=4,536)$, Feeg and Mancino (2019) reported a new graduate RN national employment rate of $86.7 \%$, which indicates a decrease from the previous two years, $88.1 \%$ in 2017 and $89.0 \%$ in 2018. Regional employment data indicate a similar decreasing trend with the exception of the Central Region, which shows an increase from $92 \%$ (in 2017 and 2018) to $94 \%$ (Figure 9).

\section{FIGURE 9}

\section{Employment Rates by Regions of the Country: 2009-2019}

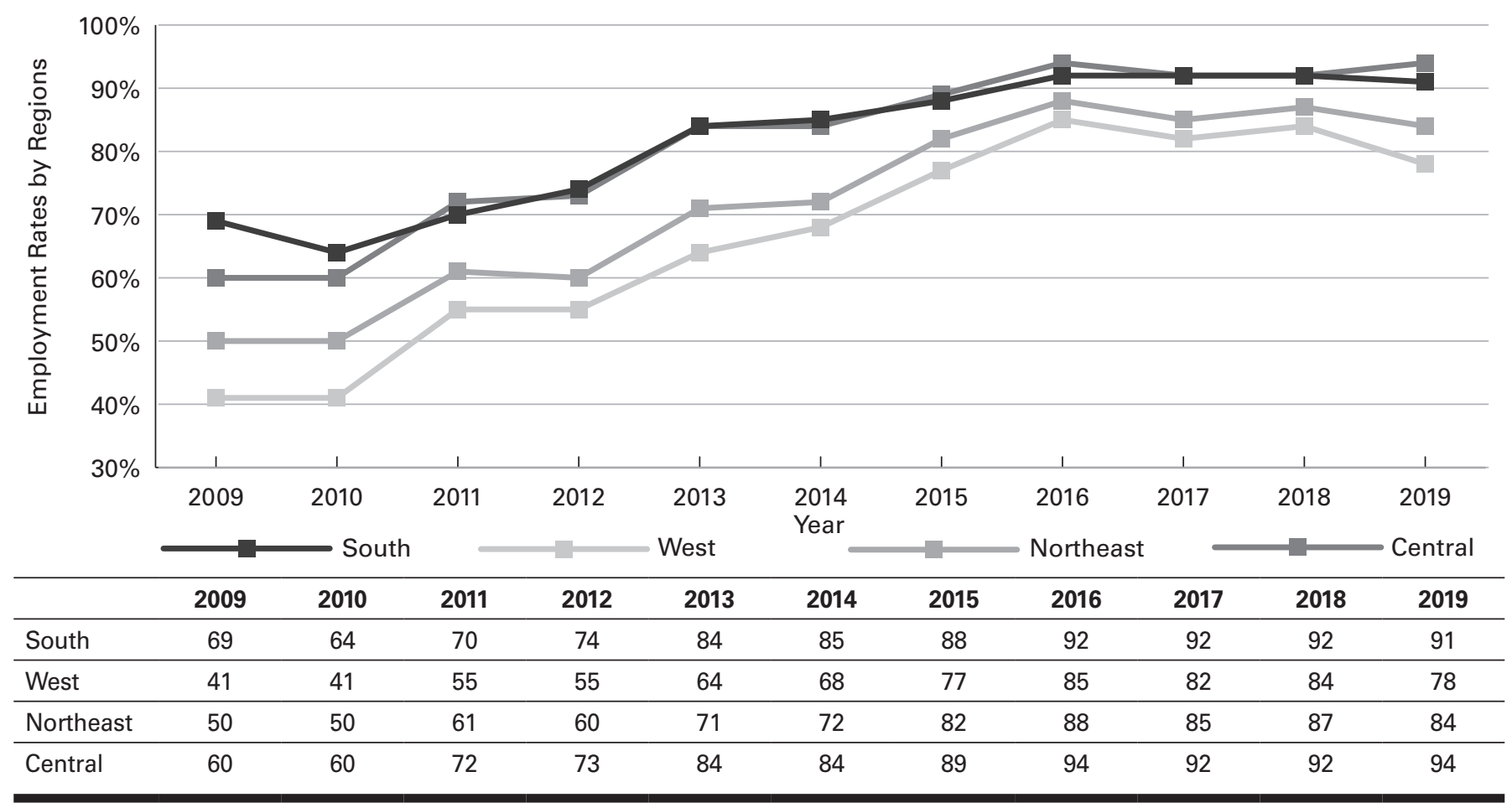


There is variation in employment rates across nursing program types and types of school ownership. Feeg and Mancino (2019) reported statistically significant differences between the employment rate of baccalaureate degree graduates (90\%) versus employment rates for associate degree (84\%) and accelerated baccalaureate degree graduates (84\%, Figure 10). Additionally, Feeg and Mancino (2019) reported a statistically significant decrease in the employment rate for private proprietary schools (83\%) compared to the previous two years (88\% in 2018 and $84 \%$ in 2017 , Figure 11).

\section{FIGURE 10}

\section{Employment by Types of Nursing Education Programs: 2017-2019}

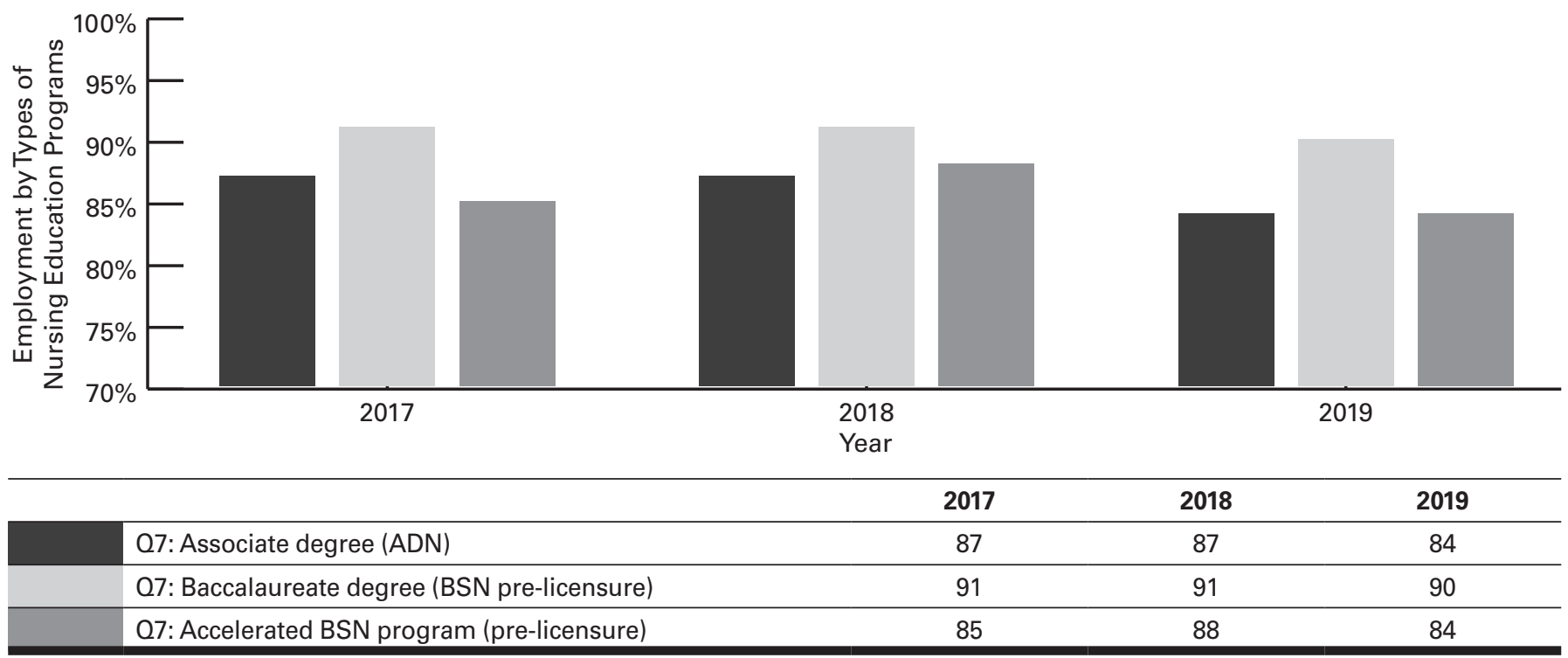

\section{FIGURE 11}

\section{Overall Employment Rates by Types of School Ownership: 2017-2019}

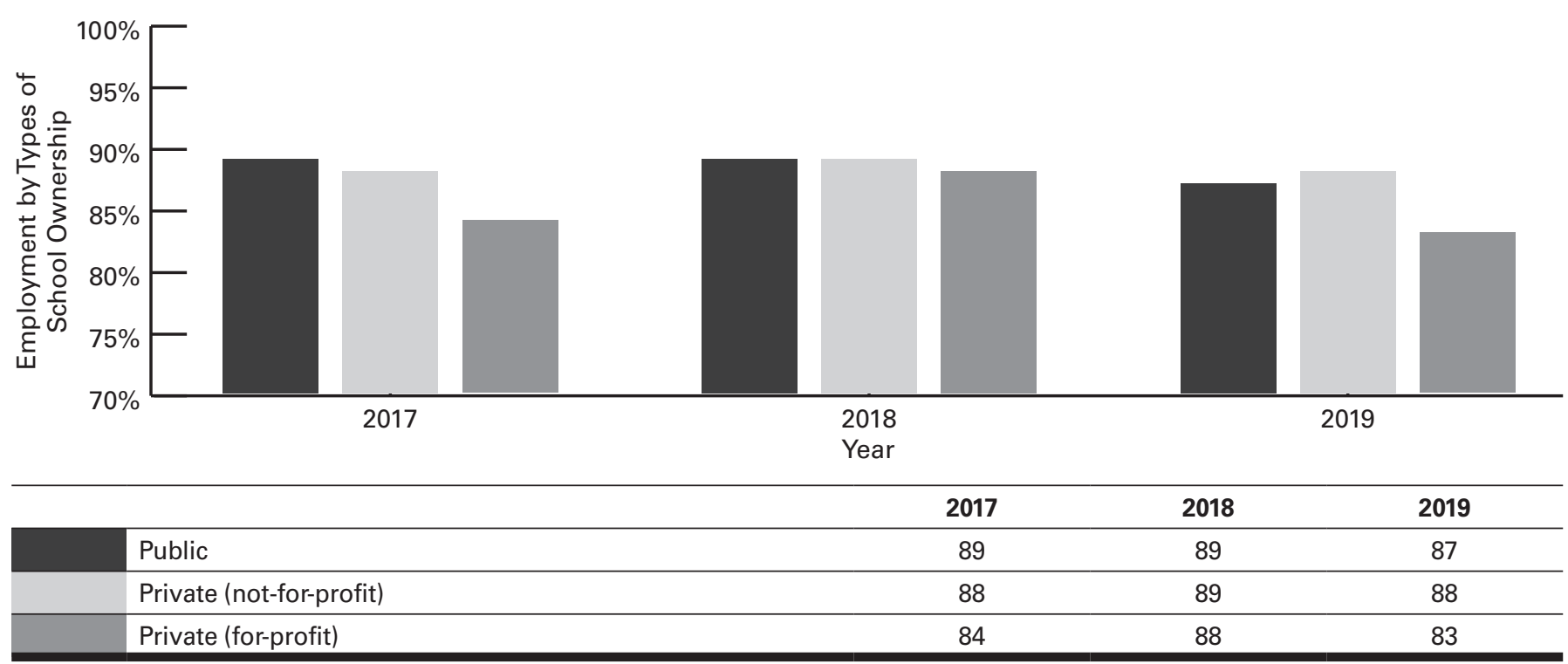

NSNA also surveyed new graduates from associate degree or diploma programs on their intent to pursue an advanced degree. Feeg and Mancino (2019) reported decreased interest from new graduates to pursue an advanced degree compared to data from 2014 (Figure 12). Despite this decreasing interest to pursue advanced education, the data show that there is a slight increase in the percentage of new graduates planning to obtain either a practice-based $(33.2 \%)$ or research-based doctorate degree $(3.4 \%)$ compared to the previous two 
years (Table 2); although, there is a decrease in the percentage of new graduates seeking a Master's degree $(36.0 \%)$ compared to prior years $(38.1 \%$ in 2018 and $40.8 \%$ in 2017).

\section{FIGURE 12}

\section{New Graduate Intent to Pursue Advanced Degree: Comparison from 2014 and 2019}

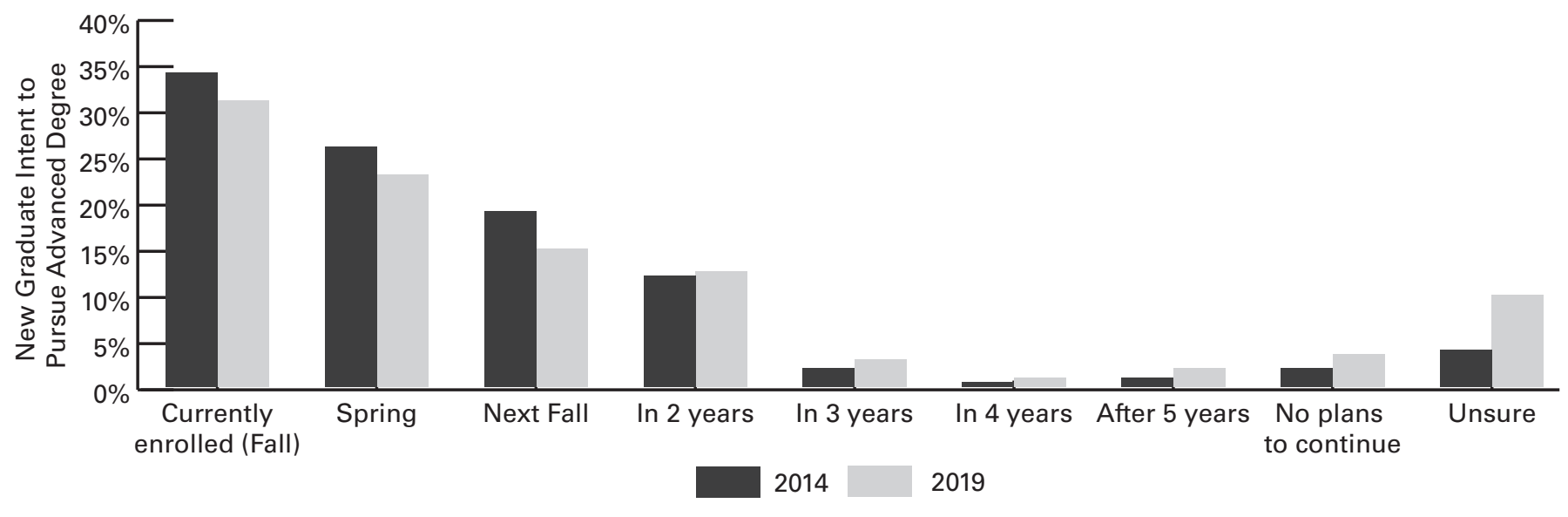

TABLE 2

Highest Degree New Graduates are Planning to Achieve: 2017 - 2019

\begin{tabular}{|c|c|c|c|c|c|c|}
\hline & & & & & & \\
\hline & \multicolumn{2}{|c|}{ Survey 2017} & \multicolumn{2}{|c|}{ Survey 2018} & \multicolumn{2}{|c|}{ Survey 2019} \\
\hline & $n$ & $\%$ & $n$ & $\%$ & $n$ & $\%$ \\
\hline Masters' degree in nursing & 1,365 & $40.8 \%$ & 1,818 & $38.1 \%$ & 1,272 & $36.0 \%$ \\
\hline Unsure & 427 & $12.8 \%$ & 721 & $15.1 \%$ & 526 & $15.0 \%$ \\
\hline Baccalaureate degree in nursing & 397 & $11.9 \%$ & 537 & $11.3 \%$ & 408 & $11.6 \%$ \\
\hline
\end{tabular}

\section{Advancing Nursing Education}

As shown above, there has been a significant increase in the number of baccalaureate-prepared nurses since the Institute of Medicine's (IOM) call to do so in 2010. In April 2019, American Association of Colleges of Nursing (AACN) published a position statement calling for academic progression and encouraging nurses to acquire at least a baccalaureate-level degree in nursing. According to the AACN, accelerated baccalaureate-degree programs are now available in 49 states and, since the release of the IOM report (2010), there has been 88 new prelicensure baccalaureate programs (AACN, 2019a). The AACN position statement (2019a) also summarizes growing evidence from the literature that baccalaureate-level nursing education has a positive impact on healthcare outcomes, specifically lowering mortality rates (Aiken, Clarke, Cheung, Sloane, \& Silber, 2003; Aiken, Clarke, Sloane, Lake, \& Cheney, 2008; Aiken et al., 2014; Aiken et al., 2017; Blegen, Goode, Park, Vaughn, \& Spetz, 2013; Cho et al., 2015; Estabrooks, Midodzi, Cummings, Ricker, \& Giovanetti, 2011; Friese, Lake, Aiken, Silber, \& Sochalski, 2008; Harrison et al., 2019; Kutney-Lee, Sloane, \& Aiken, 2013; McHugh et al., 2013; Tourangeau et al., 2007; Yakusheva, Lindrooth, \& Weiss, 2014).

The AACN surveyed schools of nursing offering prelicensure baccalaureate and master's programs about employer hiring preferences of their graduates (AACN, 2019b). The survey found that $43.2 \%$ of hospitals and other healthcare settings are requiring new graduates to have baccalaureate degrees while $82.1 \%$ have a strong preference for baccalaureate-prepared nurses.

In order to move forward toward increased academic progression, it will be critical to anticipate the potential challenges associated with this preference such as the continued need for qualified faculty (Gorski \& Polansky, 2019). 


\section{Nursing Faculty Needs}

The 2019 AACN Special Survey on Vacant Faculty Positions (Keyt, Li, \& Fang, 2019) reports the issues and trends related to nursing faculty in baccalaureate or higher nursing education. The total number of budgeted faculty positions has continued to increase since 2008 (Table 3). This year's survey data show a slight improvement in the vacancy rate $(7.2 \%)$ and the number of schools that need additional faculty members but have no vacancies $(n=475)$ compared with the 2018 data. Regional data indicate that the Midwest is experiencing the lowest vacancy rate $(6.6 \%)$ compared with other regions (Figure 13).

\section{TABLE 3}

\section{Nursing Program Full-time Faculty Positions and Needs, 2014-2019}

\begin{tabular}{|c|c|c|c|c|c|c|}
\hline & \\
\hline & 2014 & 2015 & 2016 & 2017 & 2018 & 2019 \\
\hline Budgeted faculty positions & 18,010 & 18,511 & 19,830 & 21,533 & 21,685 & 22,649 \\
\hline Number of faculty vacancies (vacancy rate) & $\begin{array}{l}1,236 \\
(6.9 \%)\end{array}$ & $\begin{array}{l}1,328 \\
(7.1 \%)\end{array}$ & $\begin{array}{l}1,567 \\
(7.9 \%)\end{array}$ & $\begin{array}{l}1,565 \\
(7.3 \%)\end{array}$ & $\begin{array}{l}1,715 \\
(7.9 \%)\end{array}$ & $\begin{array}{l}1,637 \\
(7.2 \%)\end{array}$ \\
\hline Number of faculty positions (filled rate) & $\begin{array}{c}16,774 \\
(93.1 \%)\end{array}$ & $\begin{array}{c}17,183 \\
(92.9 \%)\end{array}$ & $\begin{array}{c}18,263 \\
(92.1 \%)\end{array}$ & $\begin{array}{c}19,968 \\
(92.7 \%)\end{array}$ & $\begin{array}{l}19,970 \\
(92.1 \%)\end{array}$ & $\begin{array}{c}21,012 \\
(92.8 \%)\end{array}$ \\
\hline Number of schools with faculty vacancies & 403 & 429 & 461 & 480 & 488 & 475 \\
\hline $\begin{array}{l}\text { Number of schools with no faculty vacancies, but } \\
\text { need additional faculty }\end{array}$ & 124 & 130 & 133 & 128 & 138 & 134 \\
\hline $\begin{array}{l}\text { Number of schools with no faculty vacancies, but do } \\
\text { not need additional faculty }\end{array}$ & 187 & 182 & 220 & 224 & 245 & 284 \\
\hline
\end{tabular}

\section{FIGURE 13}

\section{Full-time Vacancy Rates by Region, 2019-2020}

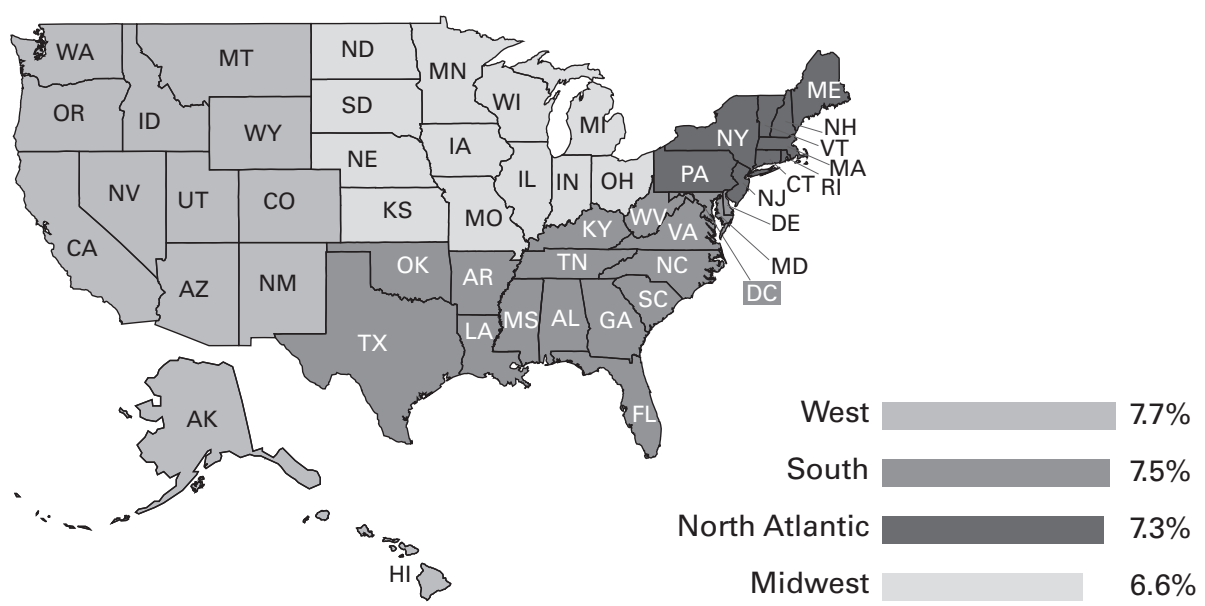

Source: Keyt et al. (2019). AACN Faculty Vacancy Survey.

According to the AACN's faculty vacancy survey (Keyt et al., 2019), the major barriers for nursing education programs not hiring new faculty members are similar to previous years and include:

- Insufficient funds to hire additional faculty

- Administration unwilling to commit to additional full-time positions

- Job competition in other marketplaces that causes an inability to recruit qualified faculty

- Unavailability of qualified applicants for faculty positions in the geographic area needed

Additionally, nursing programs continually report the following obstacles related to faculty recruitment (Keyt et al., 2019):

- Noncompetitive salaries 
- Finding faculty with the right specialty mix

- Limited pool of doctorally prepared faculty members

- Finding faculty willing and able to conduct research

- Finding faculty willing and able to teach clinical courses

- High faculty workload

The National League for Nursing's (NLN) Faculty Census Survey (2017), which reports on nursing programs at all levels of education, reports faculty vacancies in LPN/LVN, diploma, associate-degree, and baccalaureate programs and higher. Similar to AACN's faculty vacancy survey (Keyt, Li, and Fang 2019), the NLN survey indicated the main challenges in recruiting and hiring nursing faculty are not enough qualified candidates, noncompetitive salaries, and jobs in other settings more attractive than faculty positions. Keyt, Li, and Fang (2019) reported decreased institutional spending and challenging geographic areas (e.g., rural area) as additional factors impacting faculty recruitment.

These survey results provide evidence that the nursing faculty shortage persists. Consequently, qualified applicants are reportedly being turned away. NLN (2018) reported the following numbers and rates of qualified applicants being turned away by program type:

- $\operatorname{LPN} / \mathrm{LVN}(n=14,989 ; 27 \%)$

- $\operatorname{Diploma}(n=3,801 ; 29 \%)$

- Associate degree $(n=69,347 ; 38 \%)$

- Baccalaureate degree $(88,598 ; 29 \%)$

- $\mathrm{RN}$ to baccalaureate $(69,495 ; 4 \%)$

- Masters $(n=48,331 ; 9 \%)$

- Doctorate $(n=8,130 ; 15 \%)$

This shortage is projected to worsen as nursing faculty retire. The NLN survey (2017) reported that $40.2 \%$ of professors and $44.6 \%$ of chief administrators are age 61 or older; however, Fang and Kesten (2017) reported that faculty are delaying retirements since the mean retirement age in 2005-2006 was 62.2 and has increased to 65.1 in 2014-2015. Despite this delay, there is still an imperative need to address the issues of retiring faculty and the existing faculty shortage (Fang \& Kesten, 2017).

AACN (2019c) reported a 9.6\% decreasing trend of PhD enrollments from 5,122 in 2013 to 4,632 in 2017 followed by a slight increase in 2018 to 4,698. Doctor of Nursing Practice (DNP) enrollments have seen a steady increase from 3,415 in 2008 to 32,678 in 2018 (AACN, 2019d). In 2018, AACN and the National Institute of Nursing Research hosted a group discussion of academic nursing leaders to address the need to stimulate interest in $\mathrm{PhD}$ careers. Action steps resulting from that meeting include continuing the conversation with internal and external stakeholders and enhancing PhD marketing (AACN, 2019e, p. 7). To achieve these goals, AACN has been collaborating with Robert Wood Johnson Foundation, the Jonas Center, Sigma Nursing, and the National Institute of Nursing Research, and plans to approach the Hillman Scholars, the Graduate Nursing Student Academy, the American Academy of Nursing, and the Nursing Coalition. Additionally, AACN (2019f) began creating resources to help nursing schools stimulate interest in PhD careers.

\section{Emerging Education Subjects}

\section{Social Determinants of Health in Nursing Education}

Over the past few decades, there has been an increasing focus on addressing the social determinants of health (SDOH), which the World Health Organization (WHO) (World Health Organization [WHO], 2019) defines as, "the conditions in which people are born, grow, work, live, and age, and the wider set of forces and systems shaping the conditions of daily life." WHO assembled the Commission on Social Determinants of Health (CSDH) in 2005 with the objective of highlighting the role of SDOH on health and well-being and devising strategies to improve social conditions for vulnerable populations (Commission on Social Determinants of Health, 2008). The Secretary's Advisory Committee on National Health Promotion and Disease Prevention Objectives for 2020 released a report in 2010 that focuses on and provides recommendations to address SDOH (US Department of Health and Human Services, 2010). The Centers for Disease Control and Prevention (CDC) ("Social Determinants of Health," 2018) developed numerous programs addressing SDOH and provides awards for SDOH-related projects and tools to obtain SDOH data.

Moreover, there is a growing interest in adequately educating undergraduate and graduate nursing students on SDOH by threading them throughout the entire nursing curriculum and not just in community health courses (Bryant-Moore et al., 2018; NLN, 2019; Schroeder, Garcia, Phillips, \& Lipman, 2019; Thornton \& Persaud, 2018). SDOH affect patients in all settings (NLN, 2019; Thornton $\&$ Persaud, 2018). Patients often are treated for their physiologic health problems with little regard to the social factors that brought them to seek care and the social factors that will continue to affect them upon discharge. These SDOH need to be addressed in order to prevent future readmissions.

Along with the need to develop curricula addressing SDOH, NLN (2019) stresses the importance of nursing faculty being properly trained to teach SDOH and for nursing programs to create clinical partnerships with settings actively addressing social factors in their care of patients. It is necessary for students to obtain clinical experiences beyond didactic teaching strategies that will comprehensively 
demonstrate what is involved when addressing health-related social needs (Bryant-Moore et al., 2018; NLN, 2019; Schroeder et al., 2019; Thornton \& Persaud, 2018). NLN (2019) developed a vison statement that discusses these recommendations in addition to other recommendations for faculty and leadership in nursing programs to integrate SDOH into nursing education.

\section{Teaching Diagnosis}

In 1982,the North America Nursing Diagnosis Association, led by a group of nurses, was officially developed for the purpose of creating a list of diagnoses that nurses could use and incorporate into their patient care plans. For almost a decade, work continued on developing terminology, definitions, and classifications that were published and disseminated to hospitals and nursing education programs (Health Conditions, 2017). While well-intentioned and widely adopted by nurses and nurse educators, having a separate terminology for nurses has had adverse effects.

In the July issue of the Journal of Nursing Regulation, Cahill, Gleason, Harkless, Stanley, and Graber (2019) discuss the National Academy of Medicine's promotion of team-based diagnosis and the adverse outcomes resulting from nurses having their own separate terminology and not being full participants in the diagnostic process. Citing examples of missed diagnoses because the nursing notes were separate and overlooked by the rest of the healthcare team, the authors recommend that nursing programs abandon the nursing diagnosis terminology and teach students how to more fully participate in a "team-based" diagnostic process (Cahill, Gleason, Harkless, Stanley, \& Graber, 2019). (See Section on Nursing Practice for more information).

\section{Regulatory Implications}

Regulators should be aware of new models and pathways for increasing educational advancement.

When considering the faculty shortage, regulators should collaborate with educators to set minimum appropriate standards and qualifications of faculty based on evidence. Additionally, regulators should be mindful of nursing education program strategies that address their faculty shortages/vacancies such as increased hiring of DNP-prepared faculty to provide improved academic-practice partnerships.

Regulators can play an important role in promoting team-based diagnoses and removing requirements for nursing diagnoses, if they are required by the state nurse practice act (NPA) or rules/regulations. To address future needs, an emphasis should be placed on allowing all nurses to work at the maximum level of their education and ability and this begins with what is taught during nursing education.

With the growing emphasis on addressing the $\mathrm{SDOH}$, faculty will need to ensure they are obtaining and maintaining their knowledge of SDOH and adequately integrating them throughout the nursing curriculum. Leaders in nursing education will need to create meaningful partnerships with clinical settings to provide experiential learning opportunities related to SDOH. Regulators might want to consider encouraging innovative clinical experiences that will help students experience and address the SDOH.

\section{Nursing Practice}

Caroline Worthington, Director of the Florence Nightingale Museum, describes hospitals in the early balf of the 19th century as "places of last resort where the floors were laid with straw to soak up the blood" (Edge, 2010). Within 2 decades, Nightingale and other nurse leaders spearheaded the transformation of both the nursing profession and healthcare itself through unprecedented use of statistical analysis and the introduction of new processes to prevent spread of disease (Bostridge, 2015). Nurses continue to be at the forefront of change in healthcare delivery in the 21st century, when society is becoming increasingly medically complex and new solutions are needed.

\section{Team-based Diagnoses}

There has been increasing awareness on the importance of teamwork in the diagnostic process. The IOM convened the Committee on Diagnostic Error in Health Care to evaluate existing evidence on diagnostic error and develop solutions. Subsequently, the IOM released a report in 2015, Improving Diagnosis in Health Care, that emphasizes the importance of considering the diagnostic process a collaborative effort involving intraprofessional and interprofessional teamwork in addition to forming partnerships with patients and their families.

There have been increasing calls for nurses to engage in the diagnostic process and be recognized as equal members of the diagnostic team (Cahill et al., 2019; Gleason et al., 2017; Graber et al., 2017); yet, traditionally nurses were educated to use a separate nursing diagnoses, and state scope of practice regulations have not supported nurses' participation in the patient diagnostic process (Cahill et al., 2019).

Cahill and colleagues (2019) propose four recommendations to promote full participation of RNs in the diagnostic process (Table 4). These recommendations serve as next steps in moving RNs toward practicing to the fullest extent of their abilities within their scope of practice in the diagnostic process. 
TABLE 4

\section{Recommendations for Full Incorporation of RNs in the Diagnostic Process}

1. Reform state scope-of-practice regulations to support RN participation in the diagnostic process.

2. Adopt a common conceptual model of diagnosis.

3. Adopt a common language for diagnosis.

4. Designate and adopt an appropriate set of RN competencies for diagnosis.

Source: Cahill, M., Gleason, K., Harkless, G., Stanley, J., \& Graber, M. (2019). The regulatory implications of engaging registered nurses in diagnoses. Journal of Nursing Regulation, 10(2), 5-10.

\section{Telehealth}

Telehealth programs are expanding across the country and the world, with the greatest increase in rural areas, which often experience limited access to care related to a variety of challenges, such as lack of transportation, distance, and financial resources (PR Newswire, 2019). WHO believes telehealth can help improve healthcare access and outcomes, particularly for chronic disease treatment and vulnerable groups (WHO, 2019f).

A study of annual telemedicine visits among members of a large commercial insurer demonstrated a $261 \%$ increase in telemedicine visits from 2015 to 2017. The greatest increase in visits were for telemental health (53\%) followed by primary care telemedicine (39 $\%$ ) (Barnett and Ray, 2018). The Substance Abuse and Mental Health Services Administration (SAMHSA) has encouraged all certified community behavioral health clinics to use telemedicine to improve access to mental health services but also acknowledges the barriers to providers considering telehealth, \including concerns about privacy, confidentiality, technical issues, reimbursement, and variation in state law. (Substance Abuse and Mental Health Services Administration [SAMHSA], 2016).

Lack of uniformity in laws that govern telehealth across jurisdictions is a challenge for APRNs. Some states addressed telehealth regulation in NPAs, separate telemedicine acts, advisory opinions, or position statements (Garber and Chike-Harris, 2019). Some of the state regulations include APRNs specifically while others only acknowledge "other providers" as those who can provide telehealth services in their state. Before providing care via telehealth, the APRN must have a complete understanding of the pertinent laws in every state where the APRN and patients are located. When reviewing state telehealth regulations, the APRN should confirm the regulation refers specifically to APRNs or other appropriate professional title (i.e., nurse practitioner) or that "other providers" includes APRNs. As advised in a recent Telehealth and Medicine Today article, "Ensuring that telehealth laws, regulations and policies are inclusive of APRNs will encourage the successful implementation of telehealth programs and excellence in telehealth care that can be provided by APRNs" (Garber and Chike-Harris 2019).

\section{Regulatory Implications}

Allowing nurses to participate in the diagnostic process may help eliminate error, enhance the healthcare team, and allow nurses to perform a function they are already doing (nursing diagnosis). Regulators can address this by eliminating nursing diagnoses from state NPAs. Additionally, when revising their statutes and regulations, regulators can include participating in the diagnostic process as a nursing responsibility.

As telehealth services continue to expand, it is more important than ever for states to be part of the NLC. Given that practice is where the patient is and that telehealth nurses are communicating with patients across the country, the licensure process will grow more and more burdensome unless states are part of the NLC. Also, since much of the telehealth care is being provided by APRNs, the United States needs an APRN Compact more than ever.

Telehealth gives APRNs an opportunity to expand access to care for patients and increase options for clinical practice roles. Regulators should continue to work toward changing state and federal laws to reduce restrictions on APRN practice and bring uniformity to state telehealth regulations to enhance safe interstate practice.

\section{Patient Safety, Healthcare Quality, and Healthcare Delivery \\ Patient Safety}

Twenty years ago, the IOM published its landmark report, To Err is Human: Building a Safer Health System (2000), which estimated that as many as 98,000 people died in any given year from medical errors occurring in hospitals. A companion report, Crossing the Quality Chasm: A New Health System for the 21st Century (IOM, 2001) quickly followed. These reports were viewed as a wakeup call to the healthcare industry and generated the modern patient safety movement. 
Over the past 2 decades, government and institution initiatives have invested significant attention and resources towards reducing the incidence of patient harm. For example, the Agency for Healthcare Research and Quality (AHRQ) released Patient Safety Indicators that screen for adverse events that are likely preventable by changes at the system or provider level (Agency for Healthcare Research and Quality [AHRQ], 2007). The Joint Commission launched its National Patient Safety Goals ${ }^{\circledR}$ program to assist accredited organizations to address specific areas of concern regarding patient safety (The Joint Commission, 2018). The Institute for Healthcare Improvement (n.d.) established the 100,000 Lives Campaign to drive widespread adoption of six patient safety practices in U.S. hospitals to significantly reduce morbidity and mortality in American healthcare over 18 months. It later expanded its efforts to the 5 Million Lives Campaign that engaged more than 4,000 hospitals in preventing 5 million incidents of medical harm over 2 years (December 2006 to December 2008) (Institute for Healthcare Improvement, 2019). WHO’s Safe Surgery Saves Lives global challenge (WHO, 2019a) promotes use of a surgical safety checklist demonstrated by a 2009 study to decrease the postsurgical death rate from $1.5 \%$ to $0.8 \%$ and inpatient complications from $11.0 \%$ to $7.0 \%$ (Haynes, 2009).

Despite these concerted efforts, medical errors, safety lapses, and the resulting patient harm remain serious concerns. It is estimated that about one in 20 patients are exposed to preventable harm in healthcare settings worldwide. Approximately $12 \%$ of this harm causes permanent disability or death and is mostly related to medication incidents, therapeutic management, and invasive clinical procedures (Panagioti et al., 2019).

Patient safety-focused organizations are still prioritizing initiatives that mitigate preventable harm. Focused efforts by the CDC to halt healthcare-associated infections (Centers for Disease Control and Prevention [CDC], 2019a) led to an 8\% to 12\% statistically significant decrease in catheter-associated urinary tract infection, central line-associated bloodstream infection, and hospital onset Clostridioides difficile infections among acute care hospitals between 2017 and 2018 (CDC, 2019b). Yet, on any given day, about one in 31 hospital patients has at least one healthcare-associated infection, which often increases patients' length of stay, risk of death, and hospital costs (CDC, 2019c).

In October 2019, AHRQ released its most recent Patient Safety Chartbook, which is part of a family of documents and tools that constitute the National Healthcare Quality and Disparities Report (AHRQ, 2019a). This annual report to Congress mandated by the Healthcare Research and Quality Act of 1999 (P.L. 106-129) provides a comprehensive overview of the quality of healthcare received by the U.S. population (AHRQ, 2019a). The documents are based on more than 250 measures of quality and disparities covering an expansive array of healthcare services and settings from 2000 to 2017. Across a broad spectrum of measures of healthcare quality, approximately $54 \%$ of measures improved and nearly $66 \%$ of patient safety measures improved. While $77 \%$ of outcome measures improved, only $37.5 \%$ of process measures improved (AHRQ, 2019a).

\section{Disparities and Inequities}

The National Healthcare Quality and Disparities Report also examines measures related to access to care by racial and socioeconomic subgroup (AHRQ, 2019a). From 2000 to 2017, more than 50\% of access measures improved, 33\% did not improve, and 14\% declined. While the report indicated that some disparities in measures of quality were getting smaller, disparities persist, especially for poor and uninsured populations in all priority areas. Specifically, Blacks, American Indians and Alaska Natives, and Native Hawaiians/Pacific Islanders received worse care than Whites for about $40 \%$ of quality measures. In fact, disparities improved for only four measures for Blacks, two measures for American Indians and Alaska Natives, and one measure for Native Hawaiians/Pacific Islanders (AHRQ), 2019a). Hispanics received worse care than Whites for about 35\% of quality measures and disparities improved for five measures for Hispanics while Asians received worse care than Whites for $27 \%$ of quality measures and disparities improved for only two measures for Asians (AHRQ), 2019a).

These disparities are not limited to the adult population. Compared with hospitalized non-Latino White children, hospitalized Latino children experience higher rates of all adverse events, and compared with privately insured children, publicly insured children experience higher rates of preventable adverse events. Across a broad range of geographic and hospital settings, racial and/or ethnic and socioeconomic disparities exist in rates of adverse events experienced by hospitalized children (Stockwell et al., 2019). Vulnerable social groups, especially women and African Americans, are likely to experience adverse patient safety events in primary care as well as the hospitalized setting (Piccardi, Detollenaere, Bussche, \& Willems, 2018).

\section{Workplace Culture}

More than half of physicians and nurses (although varying by healthcare setting) experience symptoms of healthcare provider burnout, a syndrome "characterized by a high degree of emotional exhaustion and high depersonalization (i.e., cynicism), and a low sense of personal accomplishment from work" (Dyrbye et al., 2017, p. 1). A recent systematic review and meta-analysis revealed an association of more than $60 \%$ between burnout and patient safety permeating the work process, personal characteristics, and teamwork (Garcia et al., 2019). Factors influencing burnout included teamwork climate, work environment, workload, professional tiredness, workplace safety, job satisfaction, and personal and professional life imbalance (Garcia et al., 2019). Importantly, this review also noted that a positive 
safety culture, which includes open communication, management support, professional suitability, mutual learning, teamwork, good interpersonal relationships, and organizational workflow improvements, prevents professional fatigue (Garcia et al., 2019).

Although previously touted as a key element to improving healthcare outcomes and patient safety, electronic health records (EHRs) are a key driver of provider burnout. Studies point to the documentation time pressure associated with EHRs, which detracts from clinical care (Gesner, Gazarian, \& Dykes, 2019). The poor usability of an EHR, coupled with deficits in interprofessional team communication, creates a stressful work environment and generates ethical dilemmas (McBride, Tietze, Robichaux, Stokes, \& Weber, 2018). In response, the use of clerical support and optimizing EHR workflow through education and technical enhancements has been advised, such as applying user-centered design principles and adding machine-learning approaches to clinical decision support systems (Gesner et al., 2019; Ommaya et al., 2018).

The National Academies of Sciences, Engineering, and Medicine (2019b) recently released a critical follow-on report, Taking Action Against Clinician Burnout: A Systems Approach to Professional Well-Being. The report's two overarching themes are clinician burnout is a major problem that demands immediate action and clinician burnout is a complex multifactorial problem that is not easily solved and a systems approach to reducing clinician burnout and fostering professional well-being is required (National Academies of Sciences, 2019b). Clinician burnout and professional well-being should be considered within the context of a broader system that includes frontline delivery, the healthcare organization, the external environment, other work system factors, and individual characteristics, to impact outcomes, including patient safety. The report provides recommendations and guidelines for healthcare organizations designing, implementing, and sustaining professional well-being systems in their organizations to mitigate factors contributing to burnout (National Academies of Sciences, 2019b).

\section{Advancements in Technology \\ Artificial Intelligence}

The abundance of healthcare data collected by EHRs is giving rise to a new world of machine-learning applications for healthcare that is still in its infancy but growing rapidly. Providers, insurers, and life science companies are beginning to use artificial intelligence (AI) in innovative ways (Davenport \& Kalakota, 2019). For example, machine learning methods have proven highly accurate at diagnosing cancer via image analysis beyond what a human physician could perceive (Fakoor et al., 2013; Vial et al., 2018). IBM's Watson has been the primary exemplar of machine-based diagnosis and, while Watson's developers have looked toward AI-led treatments, most subject matter experts agree this is an ambitious goal that is far in the future (Ross \& Swetlitz, 2017).

AI-enabled automated processes, facilitated by machine learning image recognition that can read handwritten, photocopied, or faxed information, are also being used to expedite such tasks as prior authorization, billing, and patient record updates (Hussain et al, 2014). Additionally, many providers believe AI can assist in patient engagement and help offer tailored recommendations and reminders (Volp \& Mohta, 2016).

However, as attention turns to use of machine learning algorithms in healthcare, organizations must be aware that machine learning applied to clinical decision support systems can also be subject to important societal biases, and if used incorrectly, can amplify healthcare disparities (Gianfrancesco, Tamang, Tazdany, \& Schmajuk, 2018). This was true in a widely reported case in 2019 when a machine learning algorithm used by many insurers incorporated a faulty metric to determine which patients were high-risk and qualified for additional care management (Obermeier, Powers, Vogeli, \& Mullainathan, 2019). Used on over 200 million patients in the United States (Vartan, 2019), the algorithm determined risk by examining patient spending, assuming more spending meant a higher risk. However, the algorithm did not consider that poorer patients — which were more likely to be minority patients-tended to seek healthcare less often but for more emergent and complex conditions than Caucasian patients (Vartan, 2019).

AI algorithms used in other fields, such as law enforcement, academic settings, and marketing, also have displayed some degree of implicit bias (Cossins, 2018; Levin, 2019). To help slow the rapid and largely unregulated adoption of AI, large technology companies, such as Google, Amazon, and Facebook, are adopting "AI ethics boards" to guide the use of machine learning. However, many of these boards have been criticized for their makeup. Board members often do not have experience with those affected by AI bias and lack diverse representation, which may perpetuate inequality (Levin, 2019).

Healthcare regulators are also challenged by the obscure AI decision-making process and physicians are challenged to explain the rationale of an AI-based diagnosis to a patient (Davenport \& Kalakota, 2019). Moreover, future AI applications will inevitably make errors (Davenport \& Dreyer, 2019), leading to questions of what discipline or systems-based responses should be in place when errors occur, to ensure patient safety.

\section{Regulatory Implications}

The high rate of errors in healthcare continues and regulators must address these cases until we fully understand how to take a proactive approach in preventing adverse events and patient harm.

AI will have legal and ethical implications for regulators as it advances and becomes more widely used in healthcare. 


\section{Public Policy}

As the education of nurses advanced and the profession became recognized by the public for its training and professionalism, American nurse leaders saw the establishment of professional standards in statute as the next logical step for the continued improvement of both public safety and nurses' working conditions. Historic nurse leaders, such as Isabel Hampton Robb, the first president of the organizations that would eventually become the National League for Nursing and the American Nurses Association; Sopbia Palmer, founding editor of the American Journal of Nursing; and Sylveen Nye, a founder of the first state nursing association, led the charge to see the nursing profession regulated at the state level (Willis, Maples, E Britton., n.d.). In 1903, North Carolina passed the first nurse practice act in the United States to become the first state to register nurses (Egenes, n.d.).

As 2020 begins, nursing policy makers are largely focused on removing barriers to enter or remain in the nursing profession, to become licensed or employed, and to practice to the full extent of education and training. As lawmakers agree on creating policy supporting a competent and mobile workforce that meets the challenges of modern healthcare, questions arise regarding the best methods to accomplish this.

\section{Removing Barriers to the Profession: Occupational Licensure Reform}

Occupational licensing has continued to be a topic of interest at the federal and state level. While conservative groups tout the impact professional deregulation would have on workers, left-leaning reform advocates are prioritizing criminal justice reform and reentry into the workforce of those with criminal records.

Steps are being taken at the state and federal level to reform barriers to entry into an occupation. At the federal level, several pieces of legislation have been introduced in the House and Senate to address different points of state licensing reform. State-level legislation reflects a similar array of priorities.

\section{Student Loan Defaults}

U.S. student loan debt is estimated at nearly $\$ 1.6$ trillion (Bartholomae et. al., 2019) and more than 1 million borrowers default each year (Federal Student Aid, 2018). In recent years, occupational licensing agencies addressed this concern by repealing provisions for revocation of licenses for defaulting on student loans or by establishing loan repayment programs. In 2019, several states passed bills repealing these provisions (Arkansas H.B. 1296, Kentucky H.B. 118, Louisiana H.B. 423, and Texas S.B. 37) (LegiScan, 2019).

Senator Marco Rubio (R-FL) and Senator Elizabeth Warren (D-MA) introduced the Protecting Job Opportunities for Borrowers (JOBs) Act (S.B. 609/H.R. 3689, 2019). Representative Donna Shalala (D-FL) and Representative Mark Walker (R-NC) introduced the companion bill in the House. The Act would prevent states from suspending, revoking, or denying state licenses if a licensee defaults on his or her federal student loans. If the legislation passed, it would take effect in 2 years to give states time to comply with the change. The legislation also would provide for injunctive relief for aggrieved individuals by allowing them to bring a civil action in a U.S. District Court against an individual State officer in the officer's official capacity.

\section{Military Service Members and Spouse Occupational Licensing}

In another attempt to break down practice barriers, several states sought to expedite the licensure process for military spouses in a variety of ways. In 2019, Arkansas Governor Asa Hutchinson signed Senate Bill 564 allowing for automatic licensure of active service members, returning veterans, and their spouses (Moritz, 2019). Senate Bill 564 states that those in good standing with a substantially equivalent license issued by another state shall be granted an occupational license without having met licensure requirements in Arkansas.

Many states enacted bills expediting the licensing process for military spouses this session (Iowa H.B. 288, Maryland S.B. 852, Kentucky H.B. 323, Mississippi S.B. 2452, Oklahoma S.B. 670, South Dakota H.B. 1111, OR S.B. 688, and VA H.B. 2129); however, Arizona made history with House Bill 2569 when it became the first state to universally recognize all out-of-state licenses (Arizona State Board of Pharmacy, 2019). Under the new law, licenses may be issued to new Arizona residents who were licensed for at least 1 year in another state if their credentials have not been revoked, they are not the subject of any pending investigation, and they do not have a disqualifying criminal record (Sibilla, 2019). Occupations participating in an interstate compact, such as the NLC, are exempt from this legislation.

With numerous military spouse bills still pending at the state level, we can expect to see more barriers to practice lifted in the 2020 session for military personnel and their spouses.

Military spouses have also been a focus for various members of Congress. The Portable Certification of Spouses (PCS) Act (S. 1383) was introduced by Senators Tom Cotton (R-AR), Jeanne Shaheen (D-NH), and Martha McSally (R-AZ). This legislation aims to improve occupational license portability for military spouses through various methods (i.e., interstate compacts) and for a variety of professions (i.e., healthcare occupations, teachers, counselors, social workers, veterinarians, and realtors). The Department of Defense will work with and allocate funds to the Council of State Governments to develop new interstate compacts. 


\section{Criminal Justice Reform}

There continues to be bipartisan support for criminal justice reform and easing the burden on the formerly incarcerated, including expanding access to occupational licensing. No states currently have absolute bars for licensing formerly incarcerated people, but many states have restricted or limited licenses available. The more than 10,000 regulations across the United States that restrict people with criminal histories from certain types of employment are increasingly being challenged as arbitrary or ambiguous, as in the case of the often-included, but infrequently defined, phrase "good moral character" (Jan, 2019).

Senator Cory Booker (D-NJ) introduced the Next Step Act of 2019 (S. 697), which is aimed at addressing criminal justice reform and reentry of prisoners (The Next Step Act, 2019). The bill contains several major provisions including a few that pertain directly to nursing. The first of these relevant provisions, the Fair Chance Licensing Act, establishes conditions under which state and local entities are permitted to access the FBI background check system. Once passed, access to the FBI system would only be granted to states for professional licensure purposes if the requesting state has enacted a qualifying background check law. Qualifying background check laws prohibit consideration of certain aspects of an individual's criminal history when determining whether an individual qualifies for occupational licensing or employment. These aspects are:

- A conviction not directly related to the profession

- A deferred adjudication

- Participation in a diversion program

- An arrest not followed by a valid conviction

- A conviction that has been sealed, dismissed, expunged or pardoned

- A juvenile adjudication

- A misdemeanor conviction that is more than 1 year old

- A felony conviction that is more than 5 years old

If a state does not have a qualifying background check law when the bill is enacted, they would have 180 days to implement one before their access to the FBI background is revoked.

Another relevant provision of the Next Step Act, the Record Expungement Designed to Enhance Employment (REDEEM) Act of 2019, defines the crimes and individuals who are eligible for record sealing. This bill determines that nonviolent offenders who have completed their term of imprisonment and satisfied the conditions are eligible for record sealing. Those convicted on nonviolent drug offenses would receive automatic record sealing 5 years after the completion of their imprisonment, probation, or supervised released.

In congruence with this federal trend, many states introduced bills concerning the relation between an applicant's criminal history and his or her ability to get a license. In Arkansas (S.B. 451), Nevada (A.B. 319), and Utah (H.B. 90), individuals may now apply at any time for a determination of whether their criminal record would disqualify them from licensure. House Bill 1373 in Oklahoma requires occupational licensing agencies to list criminal records that would disqualify an applicant from licensure. In Maryland, a recently enacted law prohibits health occupation boards from considering only a criminal background when denying a license if 7 or more years have passed since the conviction and no new convictions occurred (H.B. 22). Additionally, a few bills specified that only offenses directly related to an occupation could result in disqualification for the occupation (Mississippi S.B. 2781 and Texas H.B. 1342).

\section{Removing Barriers to Practice: Compacts and Consensus}

At the end of 2018, the U.S. Department of Health and Human Services (HHS), the U.S. Department of the Treasury, and the U.S. Department of Labor issued Reforming America's Healthcare System Through Choice and Competition (U.S. Department of Health and Human Services [HHS], 2018b). This report identified steps the federal government and states could take to strengthen and improve the healthcare market, including reforming state scope of practice laws to allow APRNs and other nonphysician providers to have full practice authority, encouraging states to adopt interstate compacts to improve health professional license portability, and modernizing practice and payment laws at the state and federal level to allow for greater use of telehealth services.

\section{The Nurse Licensure Compact}

Since the implementation of the enhanced NLC on January 19, 2018, great progress has been made towards increasing the number of participating states. On July 1, 2019, Kansas and Louisiana implemented the NLC. During the 2019 legislative session, Alabama, Indiana, and New Jersey passed NLC bills, bringing the total compact membership to 34 states (NCSBN, 2019c). To see a full list of participating states and their implementation status, please visit www.nursecompact.com.

As borderless healthcare increases, other health professions have also adopted licensure compacts. The overarching goal of licensure compacts is to remove barriers to practice and increase access to care, especially in underserved or rural areas. The Interstate Medical Licensure Compact for physicians has been enacted in 29 states, the District of Columbia, and Guam (Interstate Medical Licensure Compact, 2019). The compact for emergency medical services personnel, The Recognition of Emergency Medical Services Personnel 
Licensure Interstate CompAct (REPLICA), has grown to 18 states (Interstate Commission for EMS Personnel Practice, n.d.), and the Physical Therapy Compact has 15 states actively issuing and accepting compact privileges (Physical Therapy Compact, n.d.).

\section{The APRN Consensus Model}

The 2019 legislative session saw various bills filed pertaining to practice and regulation of APRNs across the states. Legislation addressed advancing the Consensus Model for APRN Regulation, promotion of practice in rural and underserved areas, and various prescribing and practice issues.

Alabama and Hawaii enacted legislation promoting practice in rural and underserved areas. In Alabama, Senate Bill 37 created a loan repayment program for APRNs practicing in medically underserved areas (Ala. SB 37, 2019). In Hawaii, Senate Bill 1404 appropriates dollars to the Rural Health Care Provider Program (Haw. SB 1404, 2019).

Georgia enacted a bill to incentivize providers, including APRNs, to precept students. Students in APRN education programs often have trouble finding preceptors (GraduateNursingEdu, 2018). House Bill 287 creates a new income tax credit for those who precept without receiving compensation (Ga. H.B. 287, 2019).

Arizona, Arkansas, and Georgia enacted bills and resolutions to remove barriers for APRNs to provide care for patients in those states. In Arizona, House Bill 2068 authorized prescriptive authority for CNSs (Ariz. H.B. 2068). Prior to the enactment, CNSs were only eligible to prescribe durable medical equipment. The bill advanced CNS practice in the state, though various restrictions remain (Ariz. H.B. 2068). CNS prescribing is limited in the text of the bill to only those CNSs practicing in specific licensed healthcare institutions (Ariz. H.B. 2068, 2019). To be eligible for prescriptive authority, the bill requires CNS prescribing education and training to be "equivalent to the requirements to prescribe and dispense pharmacological agents of a registered nurse practitioner" (Ariz. H.B. 2068).

Arkansas similarly removed restrictions on APRN prescriptive authority. Prior to House Bill 1267, APRNs were unauthorized to prescribe Schedule II Controlled Substances. House Bill 1267 authorizes APRNs to prescribe up to a 5-day supply of opioids (Ark. H.B. 1267). The bill also authorizes prescriptive authority for stimulants, such as Adderall or Ritalin, if a physician initiated the treatment (Ark. H.B. 1267).

Georgia House Resolution 261 created a Joint Study Committee on Simplifying Physician Oversight of Midlevel Providers (Ga. H.R. 261). Among the preambles, the resolution states:

WHEREAS, it would be beneficial to evaluate current state laws, as well as proposed legislation to revise such laws, relating to physician oversight of physician assistants and advanced practice registered nurses to determine bow such physician oversight could be simplified and streamlined to navigate in the practice environment (Ga. H.R. 261).

The study committee may file a report with proposed legislation, though the resolution acknowledges the committee may not report any proposals (Ga. H.R. 261).

Barriers to APRN practice are also gaining notice at the federal level. On October 3, 2019, the White House sought to operationalize the Reforming America's Healthcare System Through Choice and Competition report through an Executive Order entitled, Protecting and Improving Medicare for Our Nation's Seniors. The Executive Order addresses elimination of regulatory requirements including "any Medicare licensure requirements which limit professionals from practicing at the top of their profession” (Executive Order, 2019) and directs federal agencies to remove regulatory burdens for APRNs that are more stringent than state law. Additionally, the Trump Administration is seeking to remove barriers to care delivered by nonphysicians and aligning nonphysician payment levels with those of physicians. The White House is charging the HHS to implement this Executive Order through the 2019 and 2020 Medicare payment rules.

This Executive Order calls for a review of regulatory policies that create disparities in reimbursement between physicians and nonphysician practitioners and to ensure "items and services provided by clinicians, including physicians, physician assistants, and nurse practitioners, are appropriately reimbursed in accordance with the work performed rather than the clinician's occupation" (Executive Order, 2019). Similarly, in June of 2019, the Medicare Payment Advisory Commission (MedPAC) sent a report to Congress that identified two components that impact access to primary care providers: the shortage of primary care physicians with increased reliance on NPs and PAs for primary care services, and the need to improve payment policies for APRNs, such as eliminating 'incident to' billing for APRNs and PAs (Medicare Payment and Advisory Commission [MedPAC], 2019).

Accurate billing information made available by APRN direct billing:

could create substantial benefits for the Medicare program, beneficiaries, clinicians and researchers that range from improving the accuracy of the physician fee schedule (to) reducing expenditures, enhancing program integrity, and allowing for better comparisons between the cost and quality of care provided by physicians and APRNs/PAs (MedPAC, 2019).

MedPAC estimates that allowing direct billing for APRNs would reduce Medicare spending by $\$ 50$ million to $\$ 250$ million in the first year and $\$ 1$ billion to $\$ 5$ billion over the first 5 years compared with spending under current Medicare requirements (Bendix, 2019).

Currently, APRNs and PAs can bill directly for services they provide to Medicare patients and may bill under their own National Provider Identification (NPI) number at $85 \%$ of the physician rate. The other option is to provide the exact same services but bill under 
the physician's name. If the “incident to" billing criteria are met, APRNs' and PAs' services are billed at $100 \%$ of the physician rate, under the physician name. This form of billing has contributed to a lack of accurate information about who is providing care (Perloff, DesRoches, \& Beurhaus, 2016), contributing to the chronic invisibility of APRNs in Medicare data.

MedPAC recommends eliminating "incident to" billing for APRNs and PAs and direct billing under the individual APRN provider NPI number for services provided by the APRN. If these recommendations are adopted, APRN clinical practice would be more accurately reflected in Medicare provider data. This would allow APRNs and PAs to bill Medicare directly under their own NPIs and reflect the providers who delivered the care. Previously, APRNs and PAs were required to bill under a physician's NPI for certain services, despite the physician not delivering the care.

\section{Trade and Immigration}

The United States-Mexico-Canada Agreement (USMCA) is the new trade agreement meant to replace the North American Free Trade Agreement. There are significant changes to the agreement, but the section regarding TN Visas, the reciprocal visas that allow qualifying Canadian and Mexican nurses to practice in the United States, remains the same. Chapter 16, Temporary Entry for Business Persons, Appendix 2, of the USMCA lists all professionals who are eligible to participate in the TN Visa program, including RNs (United StatesMexico-Canada Agreement, 2019). USMCA has been signed but not ratified by the three governments.

The Deferred Action for Childhood Arrivals (DACA) program has been subject to multiple court cases in the past few years. Those who have not already applied for DACA status are not eligible to apply but those who have already had DACA status are eligible for renewal. The fate of DACA is still uncertain and could potentially be resolved by the Supreme Court, which heard arguments on the case in the Fall 2019 session. Since the court cases began, several states have either questioned or clarified whether these individuals are eligible to sit for the NCLEX and obtain a license. The policies regarding their ability to sit for the NCLEX vary by state.

In November 2019, the Supreme Court heard oral arguments in the case related to the Trump Administration's move to end the DACA program. The ultimate decision will have a definite impact on the already strained nursing workforce. As of 2017, immigrants (naturalized or legal noncitizens) made up 18.2\% of all healthcare workers (Zallman, Finnegan, Himmelstein, Touw, \& Woolhandler, 2019). Regarding DACA enrollees specifically, an estimated 27,000 work in healthcare provider or support occupations, and another 200 are currently in medical school or participating in medical residencies (Svajlenka, 2019). Some healthcare organizations have expressed concern about the possible departure of tens of thousands of healthcare workers from the workforce at a time when all projections show impending shortages. Notably, the American Medical Association (AMA) pointed to the benefits in both health equity and provider diversity that DACA professionals provide, and the president of the Association of American Medical Colleges indicated that the removal of even just the physicians with DACA status would impact the care of the 5.1 million patients they would see over the course of their careers (Cunningham, 2019).

\section{School Nurses}

At the state level, another common type of bill in the 2019 legislative session centered on school nurses. For example, Colorado House Bill 1203 creates a grant program to increase the number of school nurses in public schools (Colorado General Assembly, 2019). Illinois Senate Bill 455 allows a school nurse to administer a medical cannabis product to a qualifying student (Illinois General Assembly, 2019). Since many filed bills were unable to gain traction, we can expect to see bills related to school nursing ratios and requiring public schools to have a school nurse on staff continue in the 2020 session.

\section{Veterans Affairs}

Congress is investigating and seeking to address ongoing patient safety and credentialing issues in the Department of Veterans Affairs (VA). In the fall of 2019, the House Veterans Affairs Committee Subcommittee on Oversight and Investigations held a hearing to hear from VA officials about the steps being taken to address the issues. The report follows a November 2017 Government Accountability Office study entitled, Improved Policies and Oversight Needed for Reviewing and Reporting Providers for Quality and Safety Concerns (U.S. Government and Accountability Office, 2017). The report found that between October 2013 and March 2017, the five VA Medical Centers under review had taken adverse privileging actions against nine providers that should have been reported to state licensing boards (SLBs) and the National Practitioner Data Bank (NPDB). Of those nine providers, only one was reported to NPDB and none were reported to SLBs. The report exposed a major gap in public protection that exposes veterans and other patients to potentially risky care providers.

In response to these patient safety challenges in VA facilities, the Department of Veterans Affairs Provider Accountability Act (S. 221) was introduced in the Senate. The bill would require Veterans Health Administration (VHA) facilities to report covered major adverse actions taken against a VHA provider, particularly those that affect patient safety, to the NPDB and the appropriate SLBs. The Senate Committee on Veterans Affairs held a hearing on the bill and introduction of a House companion is likely in the coming months. 
The House has released their own version of legislation to address reporting and credentialing issues, the Improving Confidence in Veterans' Care Act (H.R. 3530).

\section{Regulatory Implications}

Until the question of the legal status of DACA recipients is resolved, challenges will remain for regulators and employers as well as nursing students who may have DACA status. Questions will arise as to whether DACA recipients are permitted to take the NCLEX or become licensed as nurses, and unless clear federal guidance is forthcoming, the ability of DACA recipients to become licensed and practice will vary from state to state.

Over the past 2 years, the VA Office of Nursing Services has sought to better monitor the license and discipline status of VA nurses in real time through the implementation of Nursys. Regulators are encouraged to work with their state VA facilities to ensure complaints of unsafe nurses are filed with the BON. Nearly 20 VHA facilities have implemented Nursys e-Notify to date.

\section{Social Issues Affecting Nursing Regulation}

Historically, nurses have been the providers most in tune with the way social determinants were affecting the health of their patients. Florence Nightingale was so effective at proving that lack of sanitary conditions was increasing patient morbidity that programs to improve sanitation in India were embraced by the colonial government as a result (Bostridge, 2015). In the United States, nurses were at the forefront of public health, contributing to the containment of the 1918 flu pandemic when physicians could not manage containment and prevention, and educating on maternal and infant bealth in vulnerable communities (Lindley, 2012).

The nation's continued struggle with opioid use and increasing use of medical and recreational marijuana as well as the unknown health outcomes of its use are only a few of the social issues that will affect nursing in 2020. New conscience and religious freedom legislation will also affect nurses and nursing practice.

\section{Opioids}

The nation continues to struggle with opioid use. CDC data indicate that from 1999 to 2017, more than 702,000 people died of a drug overdose. Drug overdoses are a leading cause of injury-related death in the United States, exceeding yearly deaths from car crashes, AIDS, and guns (CDC, 2019a). Provisional 2018 CDC data indicate that although total drug overdose deaths in the United States decreased by approximately 5\% in 2018 - the first decrease since 1990 - there were more than 68,000 deaths from drug overdoses in 2018 (CDC, 2019a). A major factor in the overall decrease in drug overdose deaths is attributed to a decline in prescriptions for opioid painkillers. Additionally, addiction and law enforcement experts attribute the overall decrease to drug users having access to treatment, including naloxone, as well as an increased awareness about the immense danger of fentanyl (Goodnough, Katz, \& Sanger-Katz, 2019). CDC data show fatal overdoses involving other drugs, such as synthetic opioid fentanyl and methamphetamine, continue to rise (CDC, 2019 a).

Data from SAMHSA's National Survey on Drug Use and Health (NSDUH) show prescription pain reliever misuse was the second most common form of illicit drug use in the United States in 2018, with 3.6\% of the population misusing pain relievers. NSDUH estimates that in 2018, 10.3 million people age 12 or older misused opioids in the past year additionally, the NSDUH data indicate more than 2 million people had an opioid use disorder in 2018, including 1.7 million people with a prescription pain reliever use disorder and a half-million million people with a heroin use disorder (SAMSHA, 2019).

\section{Initiatives Addressing the Opioid Epidemic}

Several initiatives impacting nursing and regulators aimed at preventing and treating opioid addiction were announced in 2019.

A report from the National Academies of Sciences, Engineering, and Medicine (2019a) states that medications to treat opioid addiction are effective and save lives, but barriers prevent broad access and use. The report also notes that patients with opioid use disorder who receive Food and Drug Administration (FDA)-approved medications methadone, buprenorphine, and extended release naltrexone are less likely to die from overdose or other addiction-related causes, have higher treatment retention rates, and have better long-term outcomes (National Academies of Sciences, 2019a). However, these statements remain controversial as some believe dependency on one drug is being replaced by another.

HHS released new guidance recommending clinicians strongly consider prescribing or coprescribing naloxone to all patients at risk for opioid complications, including overdose (U.S. Department of HHS, 2018a). An advisory panel to the FDA recommended coprescribing the opioid reversal drug naloxone along with opioids. In addition, to encourage drug companies to enter the over-thecounter market and increase access to naloxone, the FDA developed a model drug facts label for use with a nasal spray and one for use with an auto-injector. This is the first time the FDA proactively developed and tested a drug facts label to support development of an over-the-counter product (Brooks, 2019). 
In October 2018, Congress passed the Substance Use-Disorder Prevention that Promotes Opioid Recovery and Treatment for Patients and Communities Act (SUPPORT Act). This major piece of legislation is aimed at addressing the opioid crisis through many facets. A key part of the legislation required the U.S. Drug Enforcement Administration (DEA) to issue a final rule on when providers are eligible to prescribe control substances via telehealth. The DEA was given 1 year from the passage of the SUPPORT Act to finalize this rule; however, it did not meet that deadline. The DEA proposed rule is expected to be released by the end of 2019.

Some federal entities are increasing funding for opioid programs. The Helping to End Addiction Long-term Initiative (HEAL) aims to prevent opioid misuse, develop new addiction treatments, and make "effective treatments accessible to the over 2 million people with opioid use disorder in the U.S., as well as providing new solutions and new hope to the 50 million people suffering from chronic pain." In 2019, approximately 375 HEAL grants, contracts, supplements, and cooperative agreements in 41 states totaling $\$ 495$ million were awarded (National Institute on Drug Abuse, 2019b). HHS also announced more than $\$ 1.8$ billion in funding to expand access to treatment and support near real-time data on the opioid overdose crisis (U.S. Department of HHS, 2019b).

HHS revised federal regulations governing the confidentiality of patient records created by federally assisted substance use disorder treatment programs to support coordinated care among providers who treat substance use disorder, while maintaining privacy safeguards for patients seeking treatment (U.S. Department of HHS, 2019). The Centers for Medicare and Medicaid Services (CMS) introduced new Medicare Part D opioid safety policies to reduce prescription opioid misuse, including improved pharmacy safety alerts for beneficiaries filling initial opioid prescriptions or receiving high doses of prescription opioids (Centers for Medicare and Medicaid Services [CMS], 2019a); and CMS also issued guidance as part of Congress' 2018 opioid legislation mandating state Medicaid programs and private Medicaid insurers monitor opioid use and flag potential abuse (CMS, 2019b). The DEA announced an enhanced tool, part of the Automated Reports and Consolidated Orders System, to help more than 1,500 registered drug manufacturers and distributors in the United States to more effectively identify potential illicit drug diversion (U.S. Drug Enforcement Administration, 2019a).

\section{Medication-Assisted Treatment}

The SUPPORT Act expanded the 2016 Comprehensive Addiction and Recovery Act (CARA), which authorized NPs to prescribe buprenorphine in an office-based setting for substance use disorder. The SUPPORT Act permanently allows NPs to prescribe medicationassisted treatments (MATs) and allows the other APRN roles (CNSs, CNMs, CRNAs) to prescribe MATs until October 2023. As of May 2019, over 11,000 NPs obtained waivers (Dieperink, \& DePaepe, C. (2019).

A recent analysis by the American Academy of Nurse Practitioners found restrictive practice regulations negatively influence the number of MAT waivers granted, with fewer being issued in non-full practice authority states as compared to those with full practice authority. These findings indicate the potential for reduced access to opioid use disorder treatment in more restrictive states (Diepernick \& DePaepe 2019).

As the opioid crisis continues, states have enacted various measures to combat overprescribing and addiction. The bills include those addressing prescription monitoring programs, substance use treatment programs, and MATs. Delaware enacted House Bill 220, adding parity for MATs to the state's Mental Health Parity Laws (Del. H.B. 220). "MAT therapies are often not covered under private health insurance, jeopardizing the long-term recovery plans of individuals who can no longer afford MAT therapy" (Del. H.B. 220). Increasing access to treatment of MAT extended to Texas' House Bill 1564, which authorized Medicaid reimbursement for APRNs prescribing MAT (Tex. H.B. 1564).

\section{Cannabis Research}

Research on marijuana would provide clarity regarding its use, effectiveness, administration, and dosing; however, research continues to be restricted.

Since cannabis is classified as a Schedule I Controlled Substance, it is implied that cannabis has no accepted medical value and presents a high potential for abuse, but it also places severe restrictions on cannabis research (Comprehensive Drug Abuse Prevention and Control Act, 1970). Numerous federal bills have been introduced since 1970 to amend the Controlled Substances Act (CSA) by rescheduling cannabis to allow for more research. Various petitions have been filed with the DEA to reschedule cannabis, and several lawsuits have challenged the constitutionality of including cannabis in the CSA. No bill, petition, or lawsuit has prevailed in rescheduling cannabis.

In 2016, the DEA again denied the petition to reschedule cannabis as a Schedule II Controlled Substance (Rosenberg, 2016b). The DEA; however, did recognize the lack of scientific study on cannabis and announced a policy change to expand the number of DEA-registered cannabis manufacturers (Rosenberg, 2016a). This expansion was expected to provide an increased supply of cannabis for FDA-authorized research purposes. Thirty-three entities applied to the DEA to become cannabis manufacturers for research, yet as of July 2019, no applications have been reviewed by the DEA (Scottsdale Research Institute, LLC, 2019). In June 2019, a petition sought to compel the DEA to process the applications, claiming it has unlawfully failed to act (In re Scottsdale Research Institute, LLC, 2019). A federal court in July 2019 ordered the DEA to respond within a month (U.S. Court of Appeals, 2019). The DEA responded by publishing a policy statement "providing notice of pending applications" to register as marijuana manufacturers for researchers and 
that the "DEA intends to propose new regulations that will govern the marijuana growers program for scientific and medical research" (DEA, 2019b).

Other proposed legislation would require the VA to conduct research on medical marijuana. Proposed bill House Resolution 747 would require the VA to conduct research on medicinal cannabis, including marijuana and cannabidiol, for posttraumatic stress disorder (PTSD), pain, and other conditions (To Direct the Secretary of Veterans Affairs, 2019). Proposed bills House Resolution 712 and Senate 179 would direct the VA to carry out clinical trials on the effects of medical marijuana for certain health conditions, such as chronic pain and PTSD (VA Medicinal Cannabis Research Act of 2019, H.R. 712, 116th Cong., 2019; VA Medicinal Cannabis Research Act of 2019, S. 179, 116th Cong., 2019). Proposed bill House Resolution 601 would create a pathway for the VA to obtain the marijuana needed for research by increasing the number of manufacturers registered under the CSA to manufacture cannabis for research purposes. In addition, the bill would authorize VA healthcare providers to provide recommendations to veterans on participation in federally approved cannabis clinical trials (Medical Cannabis Research Act of 2019, 2019).

\section{Influenza Vaccines and U.S. Healthcare Workers}

A review of the literature in 2019 revealed that vaccinations are not only a divisive issue in the United States but also around the world. In 2019, WHO listed vaccine hesitancy as one of the top 10 threats to global health (WHO, 2019). According to WHO, 2 to 3 million deaths are prevented each year due to vaccinations, and if global vaccination conditions and attitudes improved, 1.5 million more deaths could be prevented each year (WHO, 2019).

In the 2017-2018 winter season, influenza (flu) was responsible for the deaths of over 80,000 people in the United States, the highest reported flu-related death toll in over 40 years (CDC via AP, 2018). In the fall of 2018, the CDC's Advisory Committee on Immunization Practices recommended all healthcare personnel receive an annual flu vaccination to help reduce flu-related morbidity and mortality among healthcare personnel and their patients (CDC, 2018). Since healthcare personnel are on the frontlines interacting with patients who have the flu, it is understandable that more than half of all U.S. states have laws regarding flu shots for healthcare workers (CDC, 2019b).

A recent Illinois law (H.B. 2984) requires flu shots for healthcare personnel in jurisdictions of over 500,000 residents, with general philosophical or moral reluctance no longer being valid reasons for declining the vaccination (IL H.B. 2984). For Illinois healthcare personnel, refusing the influenza vaccine for invalid reasons may lead to suspension or firing by their healthcare facility. Medical complications or religious reasons are the only valid reasons for vaccine exemption in Illinois (IL H.B. 2984).

During the 2017-2018 flu season, the CDC directed an opt-in online panel survey of 2,265 U.S. healthcare workers and 78.4\% reported receiving the flu vaccine; however, only $44.1 \%$ reported it was an occupational requirement (CDC, 2018). Among hospital healthcare personnel, $68.3 \%$ reported the flu vaccine was an occupational requirement, which was the highest population reporting it was a requirement $(C D C, 2018)$. The CDC reports U.S. healthcare facilities are increasingly requiring healthcare workers to be vaccinated for certain diseases, including flu (CDC, 2019b). In the coming years, healthcare workers, including nurses, in hospitals, ambulatory care settings, and long-term care facilities may see changes in state vaccination laws for flu (CDC, 2019b).

\section{Conscientious Objection}

HHS finalized a rule creating a new Office for Civil Rights division within HHS that offers protections for healthcare workers to opt out of procedures when they have religious or moral objections (U.S. Department of HHS, 2019c). The rule reinforces a set of 25 laws passed by Congress that protect "conscience rights" in healthcare. Specifically, "the laws allow health care providers and entities to opt out of providing, participating in, paying for or referring for health care services that they have personal or religious objections to" (U.S. Department of HHS, 2019c). Among the procedures a healthcare worker can refuse to participate in based on personal or religious beliefs are abortions, sterilizations, and assisted suicide. Physicians, medical groups, and others have warned the rule will erode protections for vulnerable patients in healthcare (Abutaleb, 2019). In a letter to HHS, the AMA warned that "the rule would further marginalize vulnerable patient populations and stated that "conscience rights for physicians were not unlimited (American Medical Association, 2018)." The American Nurses Association (ANA) also provided a response to the new rule, stating "we must take care to balance health care professionals' rights to exercise their conscience with patients' rights to access a full range of health care services" (American Nurses Association [ANA], 2018).

The ANA also released a position statement, The Nurse's Role When a Patient Requests Medical Aid in Dying, noting that while nurses are still ethically prohibited from administering aid-in-dying medication, they should remain objective when patients are exploring this end-of-life option. According to the ANA, "Nurses have an ethical duty to be knowledgeable about this evolving issue and have the right to conscientiously object to being involved in the aid-in-dying process" (ANA, 2019).

A law in New Mexico, the Safe Harbor for Nurses Act, is intended to protect nurses from adverse action by a facility when a nurse makes a good faith request to be allowed to reject an assignment (Safe Harbor for Nurses Act, 2019). Specifically, the law "allows a nurse to reject an assignment on the basis of the nurse's assessment of his or her education, knowledge, competence or experience 
and the nurse's immediate assessment of the risk for patient safety, or violation of the nurse practice act or board of nursing rules" (Safe Harbor for Nurses Act, 2019). Additionally, the law allows a nurse to invoke the safe harbor law when he or she questions the medical reasonableness of another healthcare provider's order the nurse is required to execute. The new law applies to facilities with three or more nurses licensed by the department of health to provide healthcare on their premises. In an instance in which a nurse invokes the safe harbor law, the facility "must conduct a post-occurrence review of the situation and cannot retaliate against the nurse for invoking the safe harbor" (Safe Harbor for Nurses Act, 2019). New Mexico and Texas are currently the only two states that have safe harbor laws for nurses (Buppert, 2019).

\section{Regulatory Implications}

The ethical and legal issues of mandating vaccines may become more prominent. Hence, regulators may see some complaints filed by employers of nurses refusing to be vaccinated.

From a disciplinary perspective, it is important that regulators consider the new federal rules related to conscientious objection and what, if any, regulatory response may occur if a nurse does raise such an objection. BONs should have clear policies that distinguish between objection and abandonment and protect the rights of the nurse and of the patient to receive the full spectrum of treatment options.

\section{Summary and Conclusions}

- Growth in the RN workforce continues, although at a slower pace than in the past. More disconcerting is the LPN/LVN workforce. Fewer individuals are entering the LPN/LVN workforce and there is a decrease in the number of practical nurse programs, which could significantly impact long-term care and home health.

- It is projected that need for physicians will outpace supply; however, the number of NPs is growing rapidly. Despite the projected need and evidence that APRNs can help fill a void in care that may be left by a decreasing number of physicians, especially in rural areas, approximately 33 states still restrict APRNs from full practice authority. These states also have lower healthcare performance scores.

- The largest increase in workforce numbers is in the healthcare support occupations. Among these, the highest projected demand will be for home health aides - an indicator of where care is headed in the future.

- The National Academy of Medicine recommends that nursing education programs and healthcare facilities forgo nursing diagnoses for team-based diagnoses and allow RNs to fully participate in the diagnostic process.

- Telehealth services are rapidly expanding access to care with a focus in the areas of mental health and primary care. Lack of uniformity in telehealth laws is challenging for APRNs when they are caring for numerous patients across different states lines whose regulations all differ. Additionally, laws may be ambiguous as to whether they apply to an APRN. Some states have addressed this issue by specifically stating regulations for telehealth practice in NPAs, Telemedicine Acts, Advisory Opinions, or Position Statements.

- Despite some aggressive patient safety campaigns, it is currently estimated that about 1 in 20 patients are exposed to preventable harm in healthcare settings worldwide. Approximately $12 \%$ of this harm causes permanent disability or death and is mostly related to medication incidents, therapeutic management, and invasive clinical procedures. A positive safety culture, which includes open communication, management support, professional suitability, mutual learning, teamwork, good interpersonal relationships, and organizational workflow improvements, makes the workplace safer and prevents professional fatigue.

- Occupational licensing reform will continue to be one of the priorities in state houses during the 2020 legislative session. One of the most profound changes was found in Arizona licensure requirements, which now allow a license to be issued to new Arizona residents who were licensed for at least 1 year in another state, as long as their credentials have not been revoked, they are not the subject of pending investigations, and they do not have a disqualifying criminal record. There are plans to introduce this bill in other states during the 2020 session.

- Regulations that restrict individuals with criminal histories from certain types of employment are being challenged. The Next Step Act of 2019 (S. 697) would bring major reform to decision making related to individuals who have a criminal history. States also are focused on reforming occupational licensing laws related to past criminal history.

- Thirty-four states have now passed the NLC. Continued gains with the adoption of Consensus Model elements at the state level are also being realized.

- BONs should be prepared for both state and federal occupational licensing laws to be introduced in the coming year.

- BONs should review and update existing guidance documents in anticipation of emerging issues and trends that may affect them in the coming years. To review recent changes and revisions by BONs, see Appendix A, Board of Nursing Policy and Position Statements 


\section{References}

Abutaleb, Y. (2019). U.S. health agency finalizes conscience and religious freedom rule.

Reuters. Retrieved from https://○www.reuters.com/article/us-usahealthcare-religion/u-s-health-agency-finalizes-conscience-andreligious-freedom-rule-idUSKCN1S81PS

Agency for Healthcare Research and Quality (AHRQ). (2007). AHRQ quality indicators: Guide to patient safety indicators, v.3.1. Rockville, MD: Agency for Healthcare Research and Quality. Retrieved from https://www.qualityindicators.ahrq.gov/Downloads/Modules/PSI/ V31/psi_guide_v31.pdf

Agency for Healthcare Research and Quality (AHRQ). (2019a). 2018 national healthcare quality and disparities report. Rockville, MD: Agency for Healthcare Research and Quality. Retrieved from https:// www.ahrq.gov/research/findings/nhqrdr/nhqdr18/index.html

Aiken, L. H., Sloan, D., Griffiths, P., Rafferty, A. M., Bruyneel, L., McHugh, M....Sermeus, W. (2017). Nursing skill mix in European hospitals: Cross-sectional study of the association with mortality, patient ratings, and quality of care. BMJ Quality E Safety, 26(7), 559568.

Aiken, L. H., Sloane, D. M., Bruyneel, L., Van den Heede, K., Griffiths, P., Busse,

R....Sermeus, W. (2014). Nurse staffing and education and hospital mortality in nine European countries: A retrospective observational study. Lancet, 383(9931), 1824-30.

Aiken, L.H., Clarke, S.P., Cheung, R.B., Sloane, D.M., \& Silber, J.H. (2003). Educational levels of hospital nurses and surgical patient mortality. Journal of the American Medical Association, 290(12), 16171623.

Aiken, L.H., Clarke, S.P., Sloane, D.M., Lake, E.T. \& Cheney, T. (2008). Effects of hospital care

environment on patient mortality and nurse outcomes. Journal of Nursing Administration, 38(5), 223-229.

American Association of Colleges of Nursing. (2019a). Academic progression in nursing:

Moving together toward a bighly educated nursing workforce. Retrieved from https://catalog.slu.edu/colleges-schools/nursing/nursing-bs-rn-bsn/ aacn.pdf

American Association of Colleges of Nursing. (2019b). Employment of new nurse graduates and employer preferences for baccalaureate-prepared nurses. Retrieved from https://www.aacnnursing.org/Portals/42/News/ Surveys-Data/Research-Brief-10-19.pdf

American Association of Colleges of Nursing. (2019c). PhD in nursing. Retrieved from

https://www.aacnnursing.org/News-Information/Research-Data-Center/ $\mathrm{PhD}$

American Association of Colleges of Nursing. (2019d). Fact sheet: The doctor of nursing practice (DNP). Retrieved from https://www. aacnnursing.org/Portals/42/News/Factsheets/DNP-Factsheet.pdf

American Association of Colleges of Nursing. (2019e). The PhD pipeline in nursing. Retrieved

from https://www.aacnnursing.org/Portals/42/news/surveys-data/PhDPipeline.pdf
American Association of Colleges of Nursing. (2019f). Rounds with leadership: Taking action to champion the $P h D$ in nursing. Retrieved from https://www.newswise.com/articles/rounds-with-leadership-takingaction-to-champion-the-phd-in-nursing

American Medical Association. (2018). HHS should withdraw proposal on health care conscience rights. Retrieved from https://www.ama-assn.org/ delivering-care/ethics/hhs-should-withdraw-proposal-health-careconscience-rights

American Nurses Association. (2018). ANA responds to the HHS announcement of the new conscience and religious freedom division. Retrieved from https://www.nursingworld.org/news/news-releases/2018/anaresponds-to-the-hhs-announcement-of-the-new-conscience-andreligious-freedom-division/

American Nurses Association. (2019). The nurse's role when a patient requests medical aid in dying. Retrieved from https://www.nursingworld. org/ 49e869/globalassets/practiceandpolicy/nursing-excellence/anaposition-statements/social-causes-and-health-care/the-nurses-rolewhen-a-patient-requests-medical-aid-in-dying-web-format.pdf

Arizona State Board of Pharmacy. (2019). House Bill 2569-Occupational Licensing, Reciprocity. Retrieved from https://pharmacy.az.gov/housebill-2569-occupational-licensing-reciprocity

Association of American Medical Colleges. (2008). Physician specialty data report. Retrieved from https:/www.aamc.org/system/files/201908/2008-physician-specialty-data.pdf

Association of American Medical Colleges. (2012). Physician specialty data report. Retrieved from https://www.aamc.org/system/files/201908/2012physicianspecialtydatabook.pdf

Association of American Medical Colleges. (2014). Physician specialty data report. Retrieved from https://www.aamc.org/data-reports/ workforce/interactive-data/2014-physician-specialty-report-datahighlights

Association of American Medical Colleges. (2016). Physician specialty data report. Retrieved from https:/www.aamc.org/data-reports/ workforce/data/2016-physician-specialty-data-report-executivesummary

Association of American Medical Colleges. (2018). Physician specialty data report. Retrieved from https:/www.aamc.org/data-reports/ workforce/interactive-data/2018-physician-specialty-report-datahighlights

Association of American Medical Colleges. (2019). The complexities of medical supply and demand: Projections from 2017 to 2032. Retrieved from https://www.aamc.org/system/files/c/2/31-2019_ update_-_the_complexities_of_physician_supply_and_demand_-_ projections_from_2017-2032.pdf

Bartholomae, S., Kiss, D. E., Jurgenson, J. B., O’Neill, B., Worthy, S. L., \& Kim, J. (2019). Framing the Human Capital Investment Decision: Examining Gender Bias in Student Loan Borrowing. Journal of Family and Economic Issues, 40(1), 132-145.

Bendix, J. (2019) MedPAC calls for end to "incident to" billing. Medical Economics. Retrieved from: https://www.medicaleconomics.com/news/ medpac-calls-end-incident-billing

Blegen, M.A., Goode, C.J., Park, S.H., Vaughn, T., \& Spetz, J. (2013). Baccalaureate education in nursing and patient outcomes. Journal of Nursing Administration, 43(2), 89-94. 
Bostridge, M. (2015). Florence Nightingale: the woman and her legend. Penguin UK.

Brooks, M.A. (2019). FDA moves to fast-track OTC Naloxone for opioid overdose. Medscape. Retrieved from https://www.medscape.com/ viewarticle/907885

Bryant-Moore, K., Bachelder, A., Rainey, L., Hayman, K., Bessette, A., \& Williams, C. (2018). Use of service learning to increase master's-level nursing students' understanding of social determinants of health and health disparities. Journal of Transcultural Nursing, 29(5), 473-479.

Buppert, C. (2019). A 'safe harbor' for unsafe nursing assignments. Medscape. Retrieved from https://www.medscape.com/viewarticle/912200

Cahill, M., Gleason, K., Harkless, G., Stanley, J., \& Graber, M. (2019). The regulatory implications of engaging registered nurses in diagnoses. Journal of Nursing Regulation, 10(2), 5-10.

Centers for Disease Control and Prevention. (2018). Social determinants of health: Know what affects Health. Retrieved from https://www.cdc.gov/ socialdeterminants/index.htm

Centers for Disease Control and Prevention. (2019a). Opioids portal. Retrieved from https://www.cdc.gov/opioids/

Centers for Disease Control and Prevention. (2019b). Healthcare associated infections, data portal. Retrieved from https://www.cdc.gov/hai/data/ portal/index.html

Centers for Medicare \& Medicaid Services. (2019a). A prescriber's guide to the new Medicare Part D opioid overutilization policies for 2019. Retrieved from https://www.cms.gov/Outreach-and-Education/MedicareLearning-Network-MLN/MLNMattersArticles/Downloads/ SE18016.pdf

Centers for Medicare \& Medicaid Services. (2019b). State guidance for implementation of Medicaid drug utilization review (DUR) provisions included in section 1004 of the substance use-disorder prevention that promotes opioid recovery and treatment for patients and communities act (P.L.115-271). Retrieved from https://www.medicaid.gov/federal-policy-guidance/ downloads/cib080519-1004.pdf

Cho, E., Sloane, D. M., Kim, E. Y., Kim, S., Choi, M., Yoo, I. Y...Aiken, L. H. (2015). Effects of nurse staffing, work environments, and education on patient mortality: An observational study. International Journal of Nursing Studies, 52(2), 535-42.

Colorado General Assembly. (2019). School Nurse Grant Program. Retrieved from https://leg.colorado.gov/bills/hb19-1203

Commission on Social Determinants of Health (CSDH). (2008). Closing the gap in a generation: Health equity through action on the social determinants of health. Final Report of the Commission on Social Determinants of Health. Geneva: World Health Organization.

Comprehensive Drug Abuse Prevention and Control Act, 21 U.S.C. $\S \S$ 801-904 (1970).

Cossins, D. (2018). Discriminating algorithms: 5 times AI showed prejudice. Retrieved from https://www.americanprogress.org/issues/ immigration/news/2019/09/05/474177/know-daca-recipientsunited-states/?wpisrc =nl_health202\&wpmm $=1$

Cunningham, P.W. (2019). The Health 202: U.S. to lose thousands of health-care workers if 'dreamers' must leave. Retrived from https:// www.washingtonpost.com/news/powerpost/paloma/thehealth-202/2019/11/13/the-health-202-u-s-to-lose-thousands-ofhealth-care-workers-if-dreamers-must-leave/5dcb010788e0fa10ffd2 Odae/
Davenport, T., \& Kalakota, R. (2019). The potential for artificial intelligence in healthcare. Future healthcare journal, 6(2), 94-98. doi:10.7861/futurehosp.6-2-94

Dieperink, J., \& DePaepe, C. (2019). Nurse practitioners: Improving patient outcomes for opioid use disorder. Journal for Nurse Practitioners, 15(9), A11-A15.

Dyrbye, L. N., Shanafelt, T. D., Sinsky, C. A., Cipriano, P. F., Ommaya, A., West, C. P., \& Meyers, D. (2017). Burnout among health care professionals, A call to explore and address this underrecognized threat to safe, high quality care. NAM Perspectives. Washington, D.C.: National Academy of Medicine. doi: 10.31478/201707b

Estabrooks, C.A., Midodzi, W.K., Cummings, G.G., Ricker, K.L., \& Giovanetti, P. (2011). The impact of hospital nursing characteristics on 30-day mortality. Journal of Nurse Administration, 41(7-8 Suppl), S58-68.

Executive Order No. 13890, 84 FR 53573 (2019).

Edge, S. (2010, April 22). Florence Nightingale: the medical superstar. Retrieved from https://www.express.co.uk/expressyourself/170640/ Florence-Nightingale-the-medical-superstar

Egenes KJ. (n.d.). History of Nursing. Retrieved May 15, 2017 from http://www.jblearning.com/samples/0763752258/52258_CH01_ Roux.pdf.

Fakoor, R., Ladhak, F., Nazi, A., \& Huber, M. (2013, June). Using deep learning to enhance cancer diagnosis and classification. In Proceedings of the international conference on machine learning (Vol. 28). New York, USA: ACM.

Fang, D., \& Kesten, K. (2017). Retirements and succession of nursing faculty in 2016-2025. Nursing Outlook, 65(5), 633-642.

Federal Student Aid. (2019). Default Rates. Retrieved from https:// studentaid.ed.gov/sa/about/data-center/student/default

Feeg, V. \& Mancino, D. J. (2019). NSNA Survey of New Graduate RNs.

Friese, C.R., Lake, E.T., Aiken, L.H., Silber, J.H., \& Sochalski, J. (2008). Hospital nurse practice environments and outcomes for surgical oncology patients. Health Services Research, 43(4), 1145-1163.

Garber, K.M., Chike-Harris, K.E., (2019). Nurse practitioners and virtual care: A 50-state review of APRN telehealth law and policy. Telehealth and Medicine Today. Retrieved from: https:// telehealthandmedicinetoday.com/index.php/journal/article/view/136

Garcia, C., de Abreau, L., Ramos, J., de Castro, C., Smiderle, F., dos Santos, J., \& Bezerra, I. (2019). Influence of burnout on patient safety: Systematic review and meta-analysis. Medicina, 55, 553. doi:10.3390/medicina55090553

Gesner, E., Gazarian, P., \& Dykes, P. (2019). The burden and burnout in documenting patient care: An integrative literature review. Stud Halth Technol Inform, 21(264), 1194-1198

Gianfrancesco, M. A., Tamang, S., Tazdany, J., \& Schmajuk, G. (2018). Potential biases in machine learning algortihms using electronic health record data. JAMA Internal Medicine, 178(11), 1544-1547. doi:10.1001/jamainternmed.2018.3763

Gleason, K. T., Davidson, P. M., Tanner, E. K., Baptiste, D. L., Rushton, C. H., Day, J, Newman-Toker, D.E. (2017). Defining the critical role of nurses in diagnostic error prevention: A conceptual framework and a call to action. Diagnosis, 4(4), 201-210. 
Goodnough, A., Katz, J., \& Sanger-Katz, M. (2019). Drug overdose deaths drop in U.S. for first time since 1990. The New York Times. Retrieved from https://www.nytimes.com/interactive/2019/07/17/ upshot/drug-overdose-deaths-fall.html

Gorski, M. S., \& Polansky, P. (2019). Accelerating progress in seamless academic progression. Nursing Outlook, 67(2), 154-160.

GraduateNursingEdu.org (2018). A shortage of APRNs means a shortage of preceptors for APRN students. Retrieved from https://www. graduatenursingedu. org/2018/06/a-shortage-of-aprns-means-a-shortage-of-preceptors-foraprn-students/

Harrison, J. M., Aiken, L. H., Sloane, D. M., Carthon, J. M. B., Merchant, R. M., Berg, R. A., \& McHugh, M. D. (2019). In hospitals with more nurses who have baccalaureate degrees, better outcomes for patients after cardiac arrest. Health Affairs, 38(7), 1087-94.

Haynes, A. B., Weiser, T.G., Berry, W. R., et al. (2009). A surgical safety checklist to reduce morbidity and mortality in a global population. New England Journal of Medicine, 360, 491-499. doi:DOI: 10.1056/ NEJMsa0810119

H.B. 220, 2019 Reg. Sess. (Del, 2019).

H.B. 287, 2019 Reg. Sess. (Ga, 2019).

H.B. 1267. 2019 Reg. Sess. (Ark, 2019).

H.B. 1564, 2019 Reg. Sess. (Tex, 2019).

H.B. 2068, 2019 Reg. Sess. (Ariz, 2019).

Health Conditions. (2017). NANDA nursing diagnosis list for 20152017. Retrieved from https://health-conditions.com/nanda-nursingdiagnosis-list-2015-2017/

H.R. 261. (Ga, 2019).

Hussain, A., Malik, A., Halim, M. U., \& Ali, A. M. (2014). The use of robotics in surgery: a review. International journal of clinical practice, 68(11), 1376-1382.

Illinois General Assembly. (2019). Full Text of SB0455. Retrieved from http://www.ilga.gov

Improving Confidence in Veterans' Care Act. (2019-2020). H.R. 3530, 116th Cong.

Institute for Healthcare Improvement. (2019). Initiatives, overview. Retrieved from http://www.ihi.org/Engage/Initiatives/ Completed/5MillionLivesCampaign/Pages/default.aspx

Institute for Healthcare Improvement. (n.d.). Overview of the 100,000 Lives Campaign. Boston, MA: Institute for Healthcare Improvement.

Institute of Medicine. (2000). To err is human: Building a safer health system. Washington, D.C.: The National Academies Press.

Institute of Medicine. (2001). Crossing the quality chasm: A new health system for the 21st century. Washington, D.C.: The National Academies Press.

Institute of Medicine. (2010). The future of nursing: Leading change, advancing health. Retrieved from http://www.nationalacademies.org/hmd/ Reports/2010/The-Future-of-Nursing-Leading-Change-AdvancingHealth.aspx

Institute of Medicine. (2015). Improving diagnosis in health care. Retrieved from http://www.nationalacademies.org/hmd/Reports/2015/ Improving-Diagnosis-in-Healthcare.aspx
International Council of Nurses. (2019). 2020 year of the nurse celebrating nursing and midwifery endorsed by WHO Executive Board. Retrieved from https://www.icn.ch/news/2020-year-nurse-celebrating-nursingand-midwifery-endorsed-who-executive-board

Interstate Commission for EMS Personnel Practice. (n.d.). The EMS Compact. Retrieved from https://www.emscompact.gov/

Interstate Medical Licensure Compact. (2019). The Interstate Medical Licensure Compact. Retrieved from http://imlcc.org/

Jan, T. (2019, September 3). After prison, more punishment. Washington Post. Retrieved from https://www.washingtonpost.com/ graphics/2019/business/jobs-after-prison-rhode-island-recentlyoccupational-licensing/

Keyt, J., Li, Y., \& Fang, Di (2019). Special survey on vacant faculty positions for academic year 2019-2020. Unpublished report.

Kutney-Lee, A., Sloane, D. M., \& Aiken, L. (2013). An increase in the number of nurses with baccalaureate degrees is linked to lower rates of post-surgery mortality. Health Affairs, 32(3), 579-586.

LegiScan. (2019). Texas Senate Bill 73. Retrieved from https://legiscan. com/TX/bill/SB37/2019

Levin, S. (2019). 'Bias deep inside the code': the problem with AI 'ethics' in Silicon Valley. Retrieved from https://www.theguardian.com/ technology/2019/mar/28/big-tech-ai-ethics-boards-prejudice

Lindley, R. (2012). The forgotten American pandemic: historian Dr. Nancy K. Bristow on the influenza epidemic of 1918. Retrieved from http://hnn.us/article/146655

McBride, S., Tietze, M., Robichaux, C., Stokes, L., \& Weber, E. (2018). Identifying and addressing ethical issues with use of electronic health records. Online Journal of Issues in Nursing, 23(1), Manuscript 5. doi:10.3912/OJIN.Vol23No01Man05

McHugh, M. D., Kelly, L. A., Smith, H. L., Wu, E. S., Vanak, J. M., \& Aiken, L. H. (2013). Lower Mortality in Magnet Hospitals. Medical Care, 51(5), 382-388.

Medical Cannabis Research Act of 2019, H.R. 601, 116th Cong. (2019).

Medicare Payment and Advisory Commission. (2019). Medicare and the bealth care delivery system. Retrieved from http://medpac.gov/docs/ default-source/reports/jun19_medpac_reporttocongress_sec. pdf?sfvrsn $=0$

Moritz, J. (2019). Laws focus on military families in Arkansas; governor signs 3 bills on licensing, school access, highways. Retrieved from https://www. arkansasonline.com/news/2019/apr/20/laws-focus-on-militaryfamilies-2019042-1/

National Academies of Sciences, Engineering, and Medicine. (2019a). Medications to treat opioid addiction are effective and save lives, but barriers prevent broad access and use, says new report. Retrieved from http:// www8.nationalacademies.org/onpinews/newsitem. aspx? RecordID $=25310$

National Academies of Sciences, Engineering, and Medicine,. (2019b). Taking action against clinician burnout: A systems approach to professional well-being, . Washington, D.C.: The National Academies Press.

National Council of State Boards of Nursing. (2019a). Global regulatory atlas. Retrieved from www.regulatoryatlas.com

National Council of State Boards of Nursing. (2019c). Nurse Licensure Compact. Retrieved from https://www.ncsbn.org/nurse-licensure-compact. htm 
National Institute on Drug Abuse. (2019b). NIDA announces new NIH HEAL initiative awards to address the opioid crisis. Retrieved from https://www.drugabuse.gov/about-nida/noras-blog/2019/09/nidaannounces-new-nih-heal-initiative-awards-to-address-opioid-crisis

National Institutes of Health. (2019). A multicenter study of the immunogenicity of recombinant vesicular stomatitis vaccine for Ebola-Zaire ( $r V S V$ delta G-ZEBOV GP) for pre-exposure prophylaxis in individuals at potential occupational risk for Ebola virus exposure (PREPARE). Retrieved from https://clinicalstudies.info.nih.gov/ProtocolDetails. aspx?A_2016-I-0053.html

National League for Nursing. (2017). Faculty vacancies (Full time equivalents) by program, 2017. Retrieved from http://www.nln.org/docs/ default-source/default-document-library/faculty-vacancies-(full-timeequivalents)-by-program-2017.pdf?sfvrsn=0

National League for Nursing. (2018). National League for Nursing biennial survey of schools of nursing 2018: Percentage of qualified applications turned away by program type, 2016-2018. Retrieved from http://www.nln. org/docs/default-source/default-document-library/percentage-ofqualified-applications-turned-away-by-program-type-2016-2018(pdf).pdf? sfvrsn=0

National League for Nursing. (2019). A vision for integration of the social determinants of health into nursing education curricula. Retrieved from http://www.nln.org/docs/default-source/default-document-library/ social-determinants-of-health.pdf?sfvrsn $=2$

Nursing Now Campaign. (2018). Retrieved November 25, 2019, from https://www.who.int/hrh/news/2018/nursing_now_campaign/en/.

Nutting, A. \& Dock, L. (1907). A history of nursing: The evolution of nursing systems from the earliest times to the foundation of the first English and American training schools for nurses. New York: G.P. Putnam's Sons.

Obermeyer, Z., Powers, B., Vogeli, C., \& Mullainathan, S. (2019). Dissecting racial bias in an algorithm used to manage the health of populations. Retrieved from https://science.sciencemag.org/ content/366/6464/447

Ommaya, A. K., Cipriano, P. F., Hoyt, D. B., Horvath, K. A., Tang, P., Paz, H. L., . . Sinsky, C. A. (2018). Care-centered clinical documentation in the digital environment: Solutions to alleviate burnout. NAM Perspectives. Washington, D.C.: National Academy of Medicine. doi: $10.31478 / 201801 \mathrm{c}$

Perloff, J., DesRoches, C.M., Beurhaus, P., (2016) Comparing the Cost of Care Provided to Medicare Beneficiaries Assigned to Primary Care Nurse Practitioners and Physicians, Health Services Research, 51(4): 1407-1423.

Physical Therapy Compact. (n.d.). Compact Map. Retrieved from http:// ptcompact.org/ptc-states

Panagioti, M., Khan, K., Keers, R. N., Abuzour, A., Phipps, D., Kontopantelis, E., ... Ashcroft, D. M. (2019). Prevalence, severity, and nature of preventable patient harm across medical care settings: Systematiec review and meta-analysis. BMJ, 366(14185). doi:http://dx. doi.org/10.1136/bmj14185

Piccardi, C., Detollenaere, J., Bussche, P. V., \& Willems, S. (2018). Social disparities in patient safety in primary care: A systematic review. International Journal for Equity in Health, 17.
PR Newswire. (2019, Sept. 3). Global telemedicine market 2019-2022: expanding reimbursement and payment opportunities. Retrieved from https://www.prnewswire.com/news-releases/globaltelemedicine-market-2019-2022-expanding-reimbursement-andpayment-opportunities-300910616.html

Protecting Job Opportunities for Borrowers Act. (2019). H.R. 3689, 116th Cong.

Protecting Job Opportunities for Borrowers Act. (2019). S.B. 609, 116th Cong.

Radley, D.C., Collins, S. R., Hayes, S.L., (2019). 2019 Scorecard of State Health System Performance: Deaths for suicide, alcohol, drugs on the rise; progress expanding healthcare coverage stalls; healthcare costs are a growing burden. The Commonwealth Fund. Retrieved from: https://www.commonwealthfund.org/publications/fundreports/2019/jun/2019-scorecard-state-health-system-performancedeaths-suicide

Rosenberg, C. (2016a). Applications to become registered under the Controlled

Substances Act to manufacture marijuana to supply researchers in the United States. Retrieved from https://www.federalregister.gov/ documents/2016/08/12/2016-17955/applications-tobecomeregistered-under-the-controlled-substances-act-tomanufacturemarijuana-to

Rosenberg, C. (2016b). Denial of petition to initiate proceedings to reschedule marijuana. Retrieved from https://www.federalregister.gov/ documents/2016/08/12/2016-17960/denial-of-petition-toinitiateproceedings-to-reschedule-marijuana

Ross, C., \& Swetlitz, I. (2017). IBM pitched its Watson supercomputer as a revolution in cancer care. It's nowhere close. Stat.

Safe Harbor for Nurses Act, S.B. 82. (N.M., 2019).

S.B. 37, 2019 Reg. Sess. (Ala, 2019).

S.B. 73, 86th Legislature. (Tex, 2019).

S.B. 0455, 101st General Assembly. (Ill, 2019).

S.B.1404, 2019 Reg. Sess. (Haw, 2019).

Schroeder, K., Garcia, B., Phillips, R. S., \& Lipman, T. H. (2019). Addressing social determinants of health through community engagement: An undergraduate nursing course. Journal of Nursing Education, 58(7), 423-426.

Scottsdale Research Institute, LLC. (2019). Amended petition for a writ of mandamus. Retrieved from http://www.yettercoleman.com/ wp-content/uploads/2019/08/In-re-Scottsdale-Research-InstituteLLC.pdf

Sibilla, N. (2019). Arizona becomes first state to broadly recognize out-ofstate license. Institute for Justice. Retrieved from https://ij.org/pressrelease/arizona-becomes-first-state-to-broadly-recognize-out-ofstate-licenses/

Stockwell, D. C., Landrigan, C. P., S.L., T., Westfall, M. Y., Liu, S., Parry, G., . . S Schuster, M. A. (2019). Racial, ethnic, and socioeconomic disparities in patient safety events for hospitalized children. Hospital Pediatrics, 9(1), 1-5. doi:https://doi.org/10.1542/hpeds.2018-0131

Substance Abuse and Mental Health Services Administration. (2016). Rural behavioral health: Telehealth challenges and opportunities. In Brief, 9(2), 1-13. Retrieved from: https://store.samhsa.gov/product/ In-Brief-Rural-Behavioral-Health-Telehealth-Challenges-andOpportunities/SMA16-4989 
Substance Abuse and Mental Health Services Administration. (2019). 2018 national survey on drug use and health annual national report. Retrieved from https://www.samhsa.gov/data/report/2018-nsduhannual-national-report

Svajlenka, N. P. (2019). What We Know About DACA Recipients in the United States. Retrieved from https://www.americanprogress.org/ issues/immigration/news/2019/09/05/474177/know-daca-recipientsunited-states $/$ ?wpisrc $=$ nl_health202\&wpmm $=1$

The Joint Commission. (2018). Facts about the National Patient Safety Goals. Retrieved from https://www.jointcommission.org/facts_about_the_ national_patient_safety_goals/

The Next Step Act of 2019. S.B. 697, 116th Cong. (2019).

Thornton, M., \& Persaud, S. (2018). Preparing today's nurses: Social determinants of health and nursing education. The Online Journal of Issues in Nursing, 23(3).

To Direct the Secretary of Veterans Affairs to Conduct and Support Research on the Efficacy and Safety of Medicinal Cannabis, and for Other Purposes, H.R. 747, 116th Cong. (2019).

Tourangeau, A.E, Doran, D.M., McGillis Hall, L., O’Brien Pallas, L., Pringle, D., Tu, J.V., \& Cranley, L.A. (2007). Impact of hospital nursing care on 30-day mortality for acute medical patients. Journal of Advanced Nursing, 57(1), 32-41.

Tri-Council for Nursing. (2010). Educational advancement of registered nurses: A consensus position. Retrieved from https://img1.wsimg.com/blobby/ go/3d8c2b58-0c32-4b54-adbd-efe8f931b2df/downloads/5-2010Educational-Advancement-RNs.pdf?ver=1555011464001

United States-Mexico-Canada Agreement, U.S.-Can.-Mex. (2019). Retrieved from https://ustr.gov/trade-agreements/free-tradeagreements/united-states-mexico-canada-agreement/agreementbetween

U.S. Bureau of Labor Statistics, U.S. Department of Labor. (2019a). Occupational Outlook Handbook. Registered Nurses. Retrieved from https:// www.bls.gov/ooh/healthcare/registered-nurses.htm

U.S. Bureau of Labor Statistics, U.S. Department of Labor. (2019b). Occupational Employment Statistics. Retrieved from http://www.bls.gov/oes/ oes_emp.htm

U.S. Bureau of Labor Statistics, U.S. Department of Labor. (2019c). Occupational employment statistics: Nurse Midwives. Retrieved from https://www.bls.gov/oes/current/oes291161.htm

U.S. Bureau of Labor Statistics, U.S. Department of Labor. (2019d). Occupational employment statistics: Nurse Anesthetists. Retrieved from https://www.bls.gov/oes/2017/may/oes291151.htm

U.S. Bureau of Labor Statistics, U.S. Department of Labor. (2019e). Occupational Outlook Handbook. Nurse Anesthetists, Nurse Midwives, and Nurse Practitioners. Retrieved from https://www.bls.gov/ooh/ healthcare/nurse-anesthetists-nurse-midwives-and-nursepractitioners.htm

U.S. Bureau of Labor Statistics, U.S. Department of Labor. (2019f). Occupational employment statistics: Healthcare support occupations. Retrieved from https:/www.bls.gov/oes/current/oes310000.htm

U. S. Census Bureau. (2019). Annual estimates of the resident population for the United States, regions, states, and Puerto Rico: April 1, 2010 to July 1, 2018. Retrieved from https://www.census.gov/data/tables/timeseries/demo/popest/2010s-national-total.html

U.S. Court of Appeals for the District of the Columbia Circuit. U.S.C.A. No. 19-1120, (July 29, 2019).
US Department of Health and Human Services. (2010). Healthy People 2020: An opportunity to address societal determinants of health in the United States. Secretary's Advisory Committee on Health Promotion and Disease Prevention Objectives for 2020.

U.S. Department of Health \& Human Services. (2018a). Naloxone: the opioid reversal drug that saves lives. Retrieved from https://www.hhs.gov/ opioids/sites/default/files/2018-12/naloxone-coprescribing-guidance. pdf

U.S. Department of Health and Human Services. (2018b). Reforming America's healthcare system through choice and competition. Retrieved from: https://www.hhs.gov/about/news/2018/12/03/reforming-americashealthcare-system-through-choice-and-competition.html

U.S. Department of Health \& Human Services. (2019a). HHS 42 CFR part 2 proposed rule fact sheet. Retrieved from https://www.hhs.gov/about/ news/2019/08/22/hhs-42-cfr-part-2-proposed-rule-fact-sheet.html

U.S. Department of Health \& Human Services. (2019b). HHS announces final conscience rule protecting health care entities and individuals. Retrieved from https://www.hhs.gov/about/news/2019/05/02/hhsannounces-final-conscience-rule-protecting-health-care-entities-andindividuals.html

U.S. Department of Health \& Human Services. (2019c). Trump administration announces $\$ 1.8$ billion in funding to states to continue combating opioid crisis. Retrieved from https://www.hhs.gov/about/news/2019/09/04/ trump-administration-announces-1-8-billion-funding-statescombating-opioid.html

U.S. Department of Veterans Affairs Provider Accountability Act. (2019). S.B. 221, 116th Cong.

U.S. Drug Enforcement Administration. (2019a). DEA announces enhanced tool for registered drug manufacturers and distributors to combat opioid crisis. Retrieved from https://www.dea.gov/press-releases/2019/02/26/deaannounces-enhanced-tool-registered-drug-manufacturers-and

U.S. Drug Enforcement Administration. (2019b). DEA announces steps necessary to improve access to marijuana research. Retrieve from https://www. dea.gov/press-releases/2019/08/26/dea-announces-steps-necessaryimprove-access-marijuana-research

U.S. Government and Accountability Office. (2017). VA Health Care: Improved policies and oversight needed for reviewing and reporting providers for quality and safety concerns. Retrieved from https://www.gao.gov/ products/GAO-18-63

VA Medicinal Cannabis Research Act of 2019, H.R. 712, 116th Cong. (2019).

VA Medicinal Cannabis Research Act of 2019, S. 179, 116th Cong. (2019).

Vial, A. Stirling, D., Field, M., Ros, M., Ritz, C., Carolan, M. \& Miller, A. A. (2018). The role of deep learning and radiomic feature extraction in cancer-specific predictive modelling: a review. Translational Cancer Research, 7(3), 803-816.Volpp, K. G., \& Mohta, N. S. (2016). Patient engagement survey: improved engagement leads to better

Volpp, K. G., \& Mohta, N. S. (2016). Patient engagement survey: improved engagement leads to better outcomes, but better tools are needed. NEJM Catalyst, 2(3).

Willis D, Maples PG, Britton K. (n.d.). The Nurse Practice Act. Retrieved May 26, 2017 from https://www.rochesterregional.org/ about/history/rochester-medical-museum-and-archives/digitalexhibits/the-nurse-practice-act/. 
World Health Organization. (2019). The State of the World's Nursing report.

Retrieved from https://www.who.int/hrh/nursing_mid- wifery/stateof-the-worlds-nursing-and-midwifery-2020-get- engaged.pdf

World Health Organization. (2019a). Patient Safety, Safe Surgery: Why safe surgery is important. Retrieved from https://www.who.int/ patientsafety/safesurgery/en/

World Health Organization. (2019b). Immunization. Retrieved from https://www.who.int/news-room/facts-in-pictures/detail/immunization

World Health Organization. (2019c). Second Ebola vaccine to complement "ring vaccination" given green light in DRC. Retrieved from https:// www.who.int/news-room/detail/23-09-2019-second-ebola-vaccineto-complement-ring-vaccination-given-green-light-in-drc

Xue, Y., Kannan, V., Greener, E., Smith, J. A., Brasch, J., Johnson, B. A., \& Spetz, J. (2018). Full scope-of-practice regulation is associated with higher supply of nurse practitioners in rural and primary care health professional shortage counties. Journal of Nursing Regulation, 8(4), 5-13.

Yakusheva, O., Lindrooth, R., \& Weiss, M. (2014). Economic evaluation of the $80 \%$ baccalaureate nurse workforce recommendation: A patient-level analysis. Medical Care, 52(10), 864-869.

Vartan, S. (2019). Racial Bias Found in a Major Health Care Risk Algorithm. Retrieved from https://www.scientificamerican.com/article/ racial-bias-found-in-a-major-health-care-risk-algorithm/

Zallman, L., Finnegan, K.E., Himmelstein, D.U., Touw, S., \& Woolhandler, S. (2019) Care for America's elderly and disabled people relies on immigrant labor. Health Affairs, 38(6). Retrieved from https:// www.healthaffairs.org/doi/full/10.1377/

hlthaff. 2018.05514 ? wpisrc $=$ nl_health202\&wpmm $=1 \&$ 


\section{Appendix}

\section{APPENDIX A}

\section{Board of Nursing Policy and Position Statements}

The following is a list of the position/practice statements, clinical practice advisories, advisory/declaratory rulings, advisory opinions, and interpretive guidelines issued or revised by BONs from September 2018 through October 2019.

\section{Alaska}

- Revised the following advisory opinion: Registered Nurse Role in Self-administered Nitrous Oxide Analgesia in the Intrapartum and Immediate Postpartum Period

Arizona

- Revised the following advisory opinions: Abandonment of Patients, Administration and Monitoring of Subanesthetic IV Ketamine, Analgesia by CatheterTechniques: Role of the RN (Epidural, Intrathecal, Interpleural, Perineural), Apheresis Donor: Role of the LPN, Bone Marrow Aspiration and Biopsy, Certified Registered Nurse Anesthetists Performance of Preadmission and Pre-Procedural Comprehensive History and Physical Exam, Cervical Ripening Agents and Prostaglandin Suppositories, Chest Tubes: Removal of Pleural and Mediastinal ChestTubes, Contrast Media Injection into Coronary Arteries, Debridement, Conservative Sharp Wound, Deep Sedation, Moderate Sedation/Analgesia, Palliative Sedation, Delegation of Nursing Tasks by RN/LPN, Dual Professional \& Dual Nursing or Health Care Licensure/Certification, Flexible Sigmoidoscopy for Screening Purposes, Foot Care, Hemodialysis: The Role of the LPN, Informed Consent, IntraAortic Balloon Catheter Removal, Intrauterine Pressure Catheters (IUPC), Medical Aesthetic Procedures Performed by Licensed Nurses, Licensed Cosmetologist, Licensed Aestheticians and Certified LaserTechnologists, Orders: Accepting, Transcribing, Reviewing Orders, PreHospital Nursing, Prescription Medication Renewals Using a Nursing Protocol in an Ambulatory Setting, Sheath Removal, Placement of Mechanical Compression Devices \& Deployment of Vascular Closure Devices, Supervision of LPN By RNs, Supervision of Unlicensed Nurse Externs by RNs, Testing Guidelines for Pre-licensure Nursing Programs in AZ, Trigger Point Injection, Intraarticular Joint Injection, Facet Joint Injection, Transforaminal Epidural Injection, and Medial Branch Blocks, Vaginal Speculum Exam and Specimen Collection

\section{California RN}

- Adopted the following rule: Nurse-Midwifery Schedule II Controlled Substances to Include the Risks of Addiction and Neonatal Abstinence Syndrome with the Use of Opioids

\section{Colorado}

- Adopted the following rules: Revised Guidelines for Prescribing and Dispensing Opioids, Open Discussions
About Adverse Health Care Incidents, Sunset Medical Marijuana Program

Florida

- Adopted the following declaratory statement: APRN Using "Nurse Anesthesiologist" as a Descriptor

Hawaii

- Adopted the following Position Statement: Adverse Event Decision Pathway

Kentucky

- Revised the following advisory opinions: Roles of Nurses in Stapling, Suturing and the Application of Topical Adhesives, Employment of Nursing Students as Nursing Personnel Using Either an Academic or a "Nurse Extern" Service Model, School Nursing Practice, Recommended Course Content Infusion Therapy for Registered Nurses and Licensed Practical Nurses, Roles of Nurses in the Administration of Medication Via Various Routes, Placement of Central Lines by Nurses, Components of LPN Practice, Roles of Nurses in Endoscopic Procedures, Procedural Sedation and Analgesia

- Posted the following practice opinions: Scope of Practice of Nurses in the Performance of Bowel and Bladder Program Care, Roles of Nurses in Paracentesis Procedures, Hormone Pellet Insertion by Registered Nurses, Roles of Nurses in Thoracentesis Procedures

Nebraska

- Adopted the following advisory opinion: Procedural Sedation and Analgesia,

- Revised the following advisory opinions: Wound Debridement, Analgesia/Anesthesia by Catheter, Safe-Practice: Nursing Roles and Assignments, Sub-Anesthetic Ketamine

New Hampshire

- Revised the following position statement: Continuous Positive Airway pressure (C-PAP), Bi-level Positive Airway Pressure (Bi-PAP)

\section{North Carolina}

- Revised the following position statements: Joint Statement on Medication Management of Pain in End-of-Life Care, Telehealth/Telenursing

\section{North Dakota}

- Revised the following practice guidance statement: Abandonment

- Approved the following interpretive statements: RN scope of practice and prescribed injectable aesthetic agents; North Dakota Association of Nurse Anesthetists interpretive statement for dry needling by CRNAs in North Dakota

Ohio

- Revised the following interpretive guidelines: Insertion of Internal Jugular Venous Catheter in Adults, Guidelines 
for Conservative Sharp Wound Debridement, Guidelines for Intrapartum Monitoring of Obstetrical Patients Receiving Epidural Infusions, Guidelines for Monitoring and Management of Epidural Infusions, Guidelines for Licensed Nurse Administration of Cosmetic/Aesthetic Injectable Medications, RN Performance of a Patient Health History and Physical Examination for Purposes of Providing Nursing Care, RN Utilization of the SapiensTCS or Other Comparable Device to Confirm Peripherally Inserted Central Catheter (PICC)Tip Placement

\section{Oklahoma}

- Approved the following guidelines: Discussion Guidelines for Advanced Practice Registered Nurses When Prescribing Opioids

- Revised the following position statements and guidelines: IV Medication Administration by LPN Guidelines, Monitoring of the Moderate (Conscious) Sedation Patient by LPN Guidelines, Abandonment Statement, CRNA Inclusionary Formulary, Delegation of Nursing Functions to Unlicensed Persons, Exclusionary Formulary for APRNs with Prescriptive Authority, Wound Debridement by Licensed Nurses Guidelines

\section{Oregon}

- Approved the following interpretive statement: Infusion of Sub-Anesthetic Doses of Ketamine for Disorders of Mood, Anxiety, Trauma, and Stressors Resistant to Medication and Psychotherapy, Ketamine Opinion, Nurse Who Participates in Cosmetic Procedures, Provision of Foot Care by the RN and LPN, RN Who Teaches the Administration of Lifesaving Treatments, RN WhoTeaches Unregulated Assisted Persons How to Administer Non-injectable Medications, Telehealth Nursing, RN or LPN Who Participates in Vascular and Non-Vascular Access and Infusion Therapy

\section{South Carolina}

- Approved the following position statements: Joint Advisory Opinion Issued by the SC BON Regarding Administration of Low Dose Ketamine Infusions in Hospital Settings, Including Acute-Care, By Nurses, Recommended Age Parameters for the APRN Practicing in SC

- Revised the following advisory opinions: Scope of Practice APRN Admitting Patients to Hospital, APRN and CRNA Inserting Invasive Cardiovascular Monitoring Lines, NNPs and APRNs Performing Circumcisions on Newborns, APRNs Conducting Assessments without Physician Collaboration, Scope of Practice for Licensed Nurse Performing Certain Cosmetic Procedures, CRNAs and APRNs Inserting Invasive Cardiovascular Monitoring Lines, RN and LPN Scope of Practice Regarding Pronouncements of Death, Scope of Practice with APRNs Holding Prescriptive Authority to use EPT, APRNs with Prescriptive Authority Prescribing Medications for Immediate Family

\section{South Dakota}

- Revised the following advisory opinions: Abandonment, Intrathecal Injection of Contrast Media by CRNAs, Dele- gation Decision Making Algorithm, Dermatological Procedures by Licensed Nurses, Emergency Nursing Care, Performance of Gastric Band Adjustments by RNs, Medication Administration by RNs and LPNs, Role of the RN in Management of Patients Receiving Moderate Sedation, Performance of Limited Diagnostic Ultrasound by RNs, Sexual Assault Nurse Examiners Training

\section{Texas}

- Revised the following position statements: Nurses carrying out orders from physician assistants; Role of the LVN in the pronouncement of death; LVNs engaging in IV therapy, venipuncture, or PICC lines; Educational mobility; Nurses with responsibility for initiating physician standing orders; Board rules associated with alleged patient "abandonment"; Role of LVNs \& RNs in management and/or administration of medications via epidural or intrathecal catheter routes; Role of the nurse in moderate sedation; Performance of laser therapy by RNs or LVNs; Continuing education: Limitations for expanding scope of practice; Delegated medical acts; Use of American Psychiatric Association diagnoses by LVNs, RNs, or APRNs; Role of LVNs and RNs in school health; Duty of a nurse in any practice setting; Board's jurisdiction over a nurse's practice in any role and use of the nursing title; Development of nursing education programs; Texas Board of Nursing/Board of Pharmacy, Joint Position Statement, Medication errors; Nurses carrying out orders from APRNs; Nurses carrying out orders from pharmacists for drug therapy management; RNs in the management of an unwitnessed arrest in a resident in a long term care facility; APRNs providing medical aspects of care for individuals with whom there is a close personal relationship; Use of complementary modalities by the LVN or RN; Nurses engaging in reinsertion of permanently placed feeding tubes; Administration of medication \& treatments by LVNs; LVN scope of practice; RN scope of practice; Professional boundaries including use of social media by nurses

\section{Vermont}

- Revised the following position statements: Role of the Nurse in Delegating Nursing Interventions, Licensing Requirements for Nurses Performing Telehealth Nursing to Vermonters from Outside Vermont

Virginia

- Revised the following guidance documents: RNs or LPNs as First Assistants in Surgery, Cutting of Corns and Warts by RNs and LPNs, Use of Cervical Ripening Agents, Surveillance Activities Require by the OSHA Respiratory Standards, Patient Abandonment by Care Providers, Removal of Venous and Arterial Sheaths by Unlicensed Personnel, Authority of LPNS to Write Do Not Resuscitate Orders (DNR Orders), Transmittal of Orders by Authorized Agents, Guidelines for Prescription Drug Administration Training Program for Child Day Programs, Whether a Nurse May Administer a MedicationThat Has BeenTransmitted Orally or in Writing by a Pharmacist Acting as the Prescriber's Agent, Administration of Certain Over-theCounter Drugs by Certified Nurse Aides 
Washington

- Adopted the following advisory opinions: RN and LPN Scope of Practice, RN Delegation in School Settings: K-12 Grades, Private and Public Schools, Opioid Use Disorder - Medication Assisted Treatment: Nurse Care Managers and Scope of Practice, Mobile Anesthesia: Scope of Practice for Advanced Registered Nurse Practitioners, Administration of Cannabis/Marijuana Products in School Settings: K-12 Grades, Public and Private Schools

\section{West Virginia}

- Revised the following position statements: Criteria for Determining Scope of Practice for Licensed Nurses and Guidelines for Determining Acts that may be Delegated or Assigned by Licensed Nurses, Accepting \& Rejecting an Assignment Guidelines, Delegation Related to Medical Discharge Summary

\section{Wyoming}

- Approved the following advisory opinions: Delegation, Pre Hospital Nursing

- Revised the following advisory opinions: Amniotomy, APRN Population Focus and Definitions, Assuring Safe Health Care in Schools and Alternate Settings, Cosmetic and Dermatological Procedures, Ketamine, Nitrous Oxide Administration, Nursing and Electronic Delivery of Care, Pain Management, Scope Related to Common PharmaceuticalTasks, Practicing Below the Highest Level of Licensure/Recognition, Pre- and Post-Anesthesia Nursing Practice 